\title{
THESIS
}

\section{RENEWABLES FIRMING USING GRID-SCALE BATTERY STORAGE \\ IN A REAL-TIME PRICING MARKET}

\author{
Submitted by \\ Charles Quann \\ Department of Mechanical Engineering
}

In partial fulfillment of the requirements

For the degree of Master of Science

Colorado State University

Fort Collins, Colorado

Summer 2017

Master's Committee:

Advisor: Thomas H. Bradley

John Petro

Rodolfo Valdes-Vasquez 
Copyright by Charles Aaron Quann 2017

All Rights Reserved 


\section{ABSTRACT \\ RENEWABLES FIRMING USING GRID-SCALE BATTERY STORAGE \\ IN A REAL-TIME PRICING MARKET}

Battery storage has many benefits, such as providing instantaneous response to changes in demand, clean electricity to customers, and integration of intermittent power sources. However, at the present time battery storage has proven to be too costly for widespread implementation. While there has been research to examine the cost at which battery storage will become cost effective for particular applications, little work has been done to determine the most effective placement of battery storage for the greatest impact on the system as a whole. This research examines battery storage in a real-time pricing energy market, and compares the cost effectiveness of three different cases: (1) Battery storage owned and operated by an intermittent renewable energy generation facility, (2) Battery storage connected to the grid providing energy services, (3) Battery storage owned and operated by a manufacturing plant. Real-time pricing data from ISO New England was analyzed to determine the monetary benefits of each case on a per mega-amp-hour basis. By looking at the issue holistically, instead of analyzing isolated scenarios, the benefits of each placement can be isolated from the overall benefits of connecting storage to the grid. Once the true value of each scenario can be accurately identified, the integration of utility scale battery storage is optimized to maximize benefits to all stakeholders. The results show that the economic benefit of a battery in a real-time pricing market is not dependent on the electrical generation or consumption attached to it. Instead, a grid-connected battery makes its own business case, meaning that existing battery storage can be leveraged for arbitrage and grid services without a loss of renewables firming capabilities. 


\section{ACKNOWLEDGEMENTS}

I would like to thank Dr. Thomas Bradley for his guidance, expertise, and thoughtful feedback throughout this project. I am grateful for the knowledge that he has imparted to me both academically and professionally.

I would like to thank Dr. John Petro for his support and encouragement throughout this project and my entire master's program.

I would like to thank Dr. Rodolfo Valdes-Vasquez for his help and insight, which made this thesis stronger and more complete. 


\section{DEDICATION}

This work is dedicated to my wife, Amber Joyce Quann, who bravely joined me in this adventure, and who has fiercely loved me through it 


\section{TABLE OF CONTENTS}

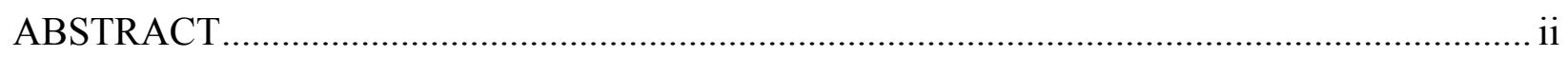

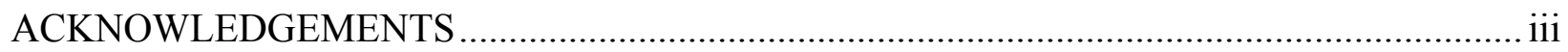

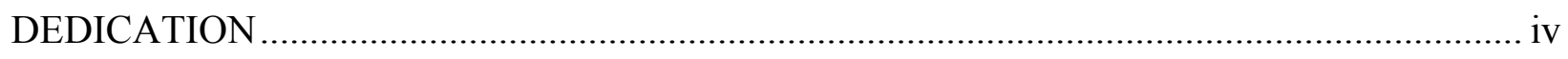

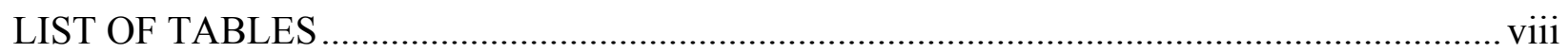

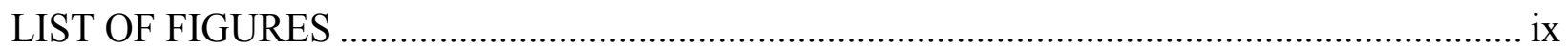

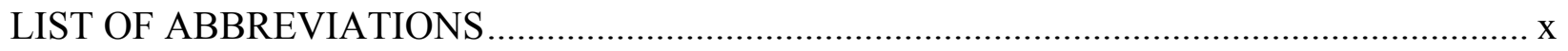

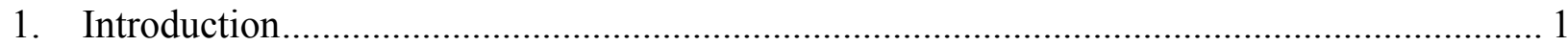

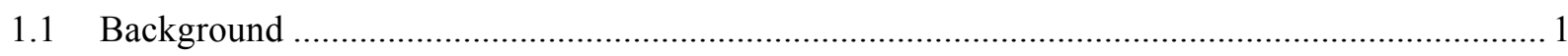

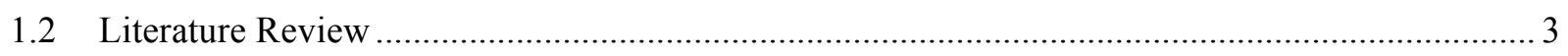

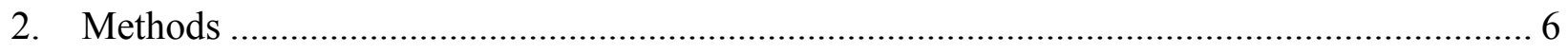

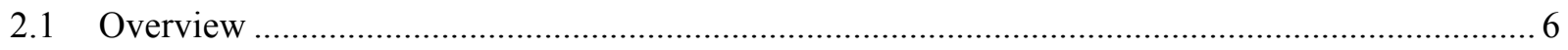

2.1.1 Case 1: Grid-Connected Battery in Pure Arbitrage Application......................................... 6

2.1.2 Case 2: Grid-Connected Battery in Renewables Firming Application ................................. 7

2.1.3 Case 3: Grid-Connected Battery in Peak Shaving Application …....................................... 8

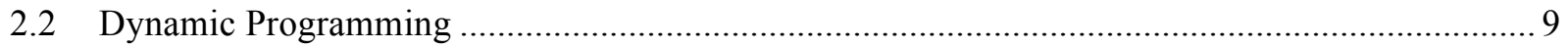

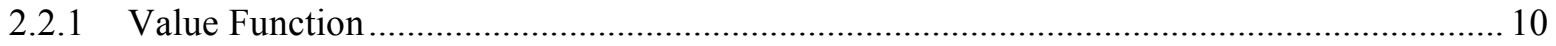

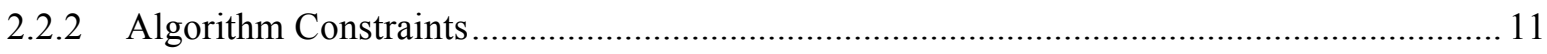

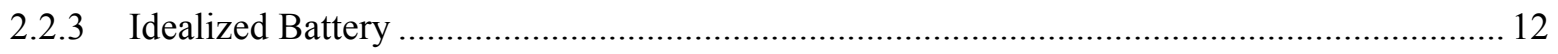

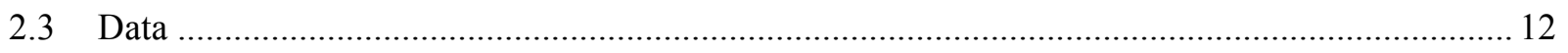

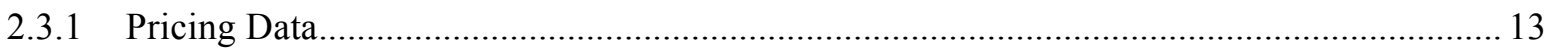

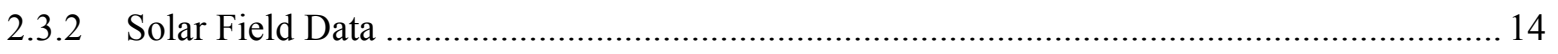

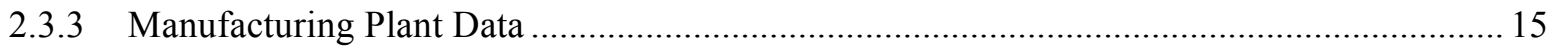

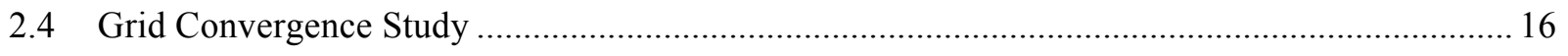




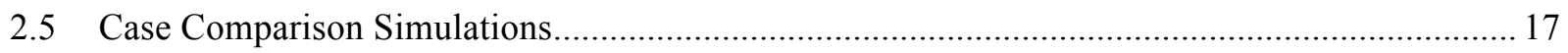

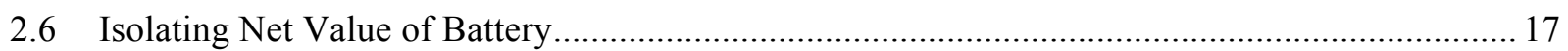

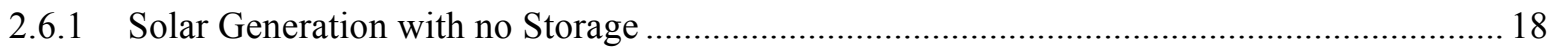

2.6.2 Manufacturing Plant Consumption with no Storage ......................................................... 18

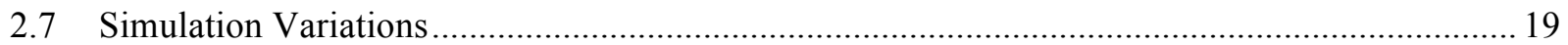

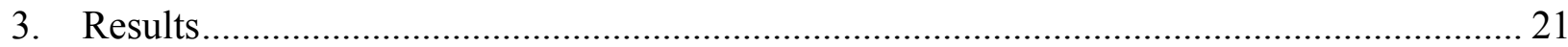

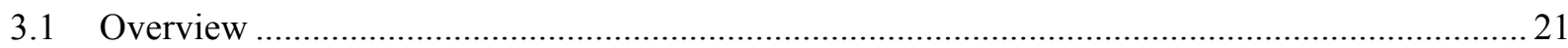

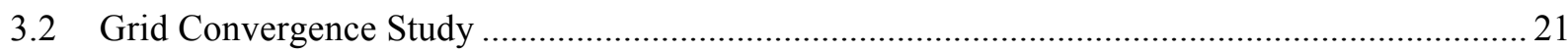

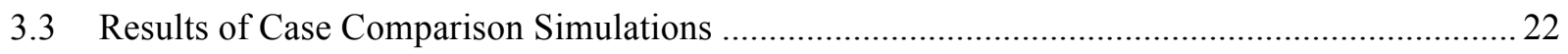

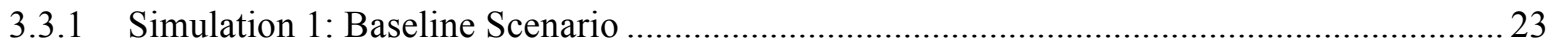

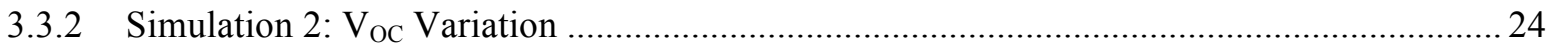

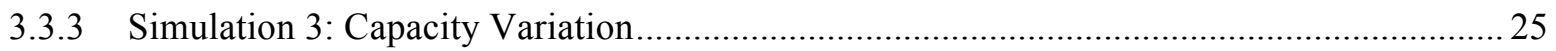

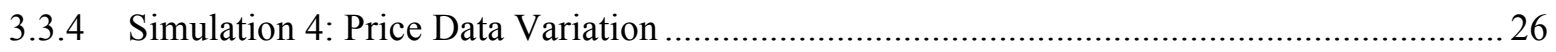

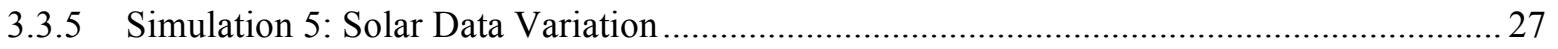

3.3.6 Simulation 6: Manufacturing Data Variation..................................................................... 27

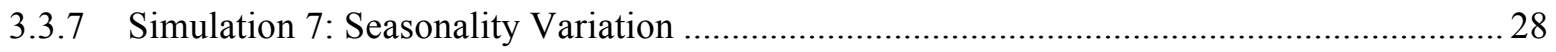

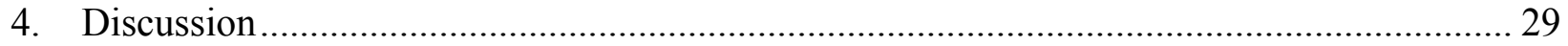

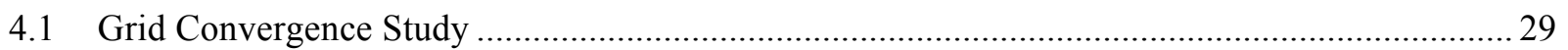

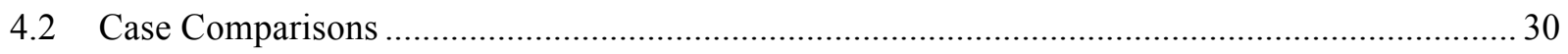

4.3 Pricing Anomalies: Primary Drivers of Economic Value ....................................................... 34

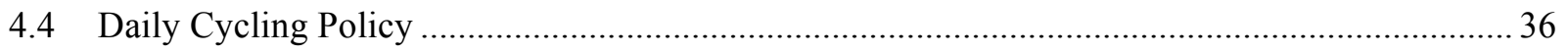

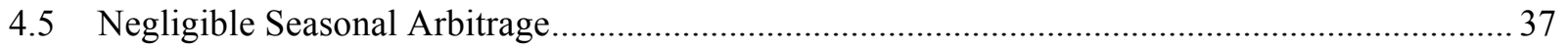

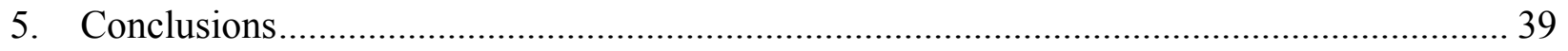

5.1 Absence of Synergistic Effect of Renewables Firming and Peak Shaving in a RTP Market ....... 39

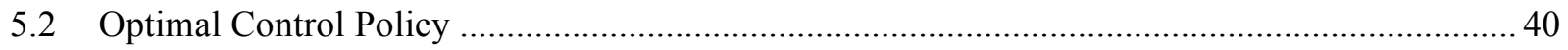


5.2.1 Primary Drivers of Economic Benefit

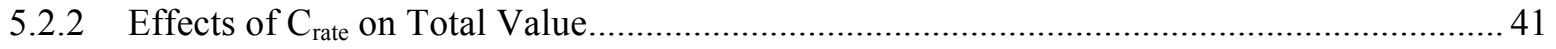

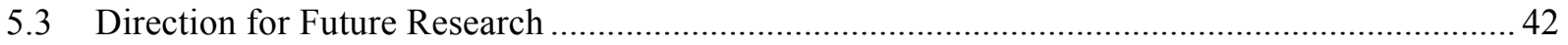

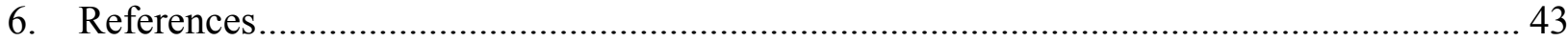

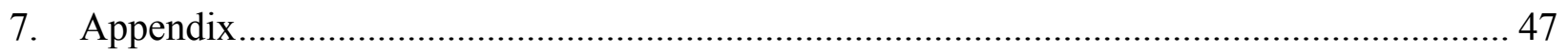

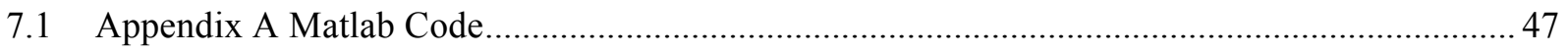




\section{LIST OF TABLES}

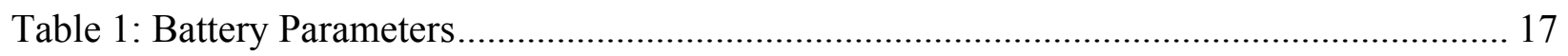

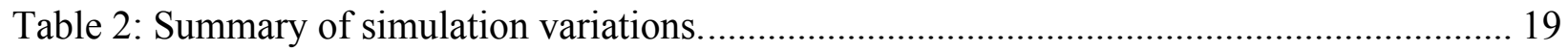

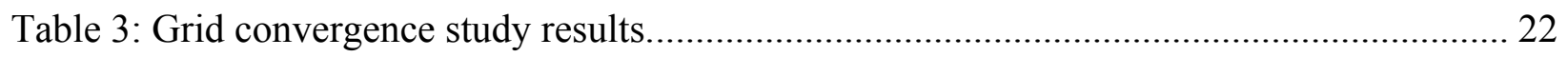

Table 4: Total value of the solar generation and manufacturing consumption ......................... 23

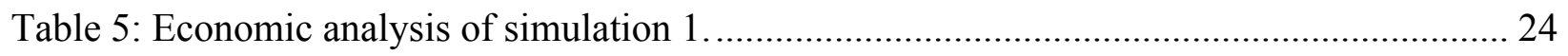

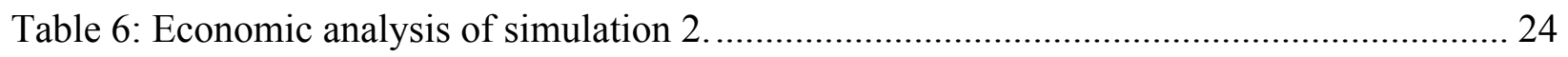

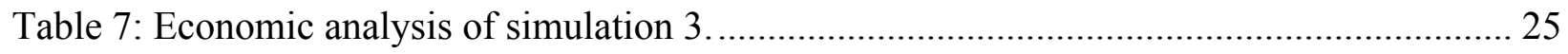

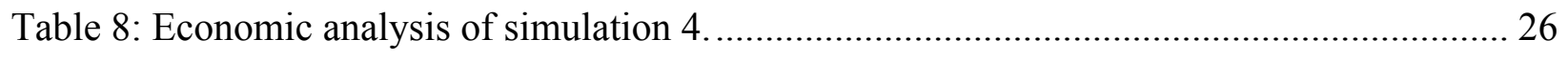

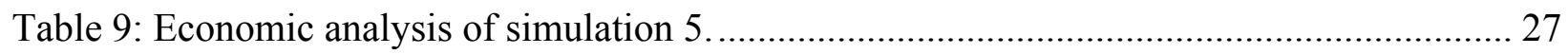

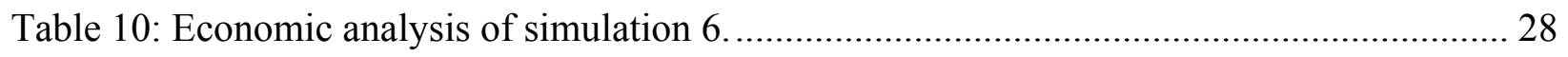

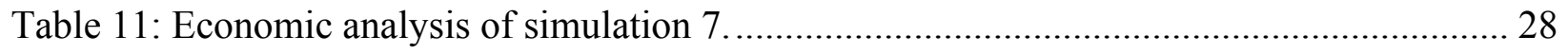

Table 12: Relative error of the grid convergence study....................................................... 29

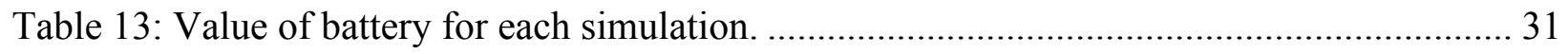




\section{LIST OF FIGURES}

Figure 1: Case 1, stand alone grid-connected battery operating in pure arbitrage. ……................. 7

Figure 2: Case 2, solar array with grid-connected battery storage. ………………................... 7

Figure 3 : Case 3 , manufacturing plant with grid-connected battery storage ............................... 8

Figure 4: Sample of pricing data from ISO New England 15-minute final LMP. ...................... 13

Figure 5: Sample solar data from Christman Field Phase 1....................................................... 14

Figure 6: Sample of manufacturing plant data from ENERNOC Open Data................................ 15

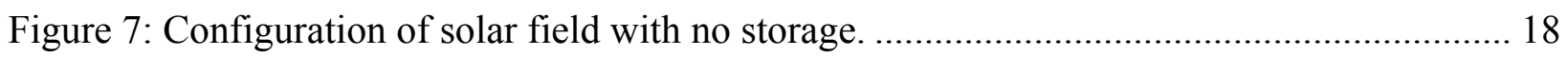

Figure 8: Configuration of manufacturing plant without storage. …………………................. 19

Figure 9: Example results showing battery function over a single day.................................... 22

Figure 10: Effect of increasing the C-rate on the total value obtained through arbitrage. ............ 30

Figure 11: Battery storage energy to discharge during price spike event..................................... 34

Figure 12: Negative pricing event. SOC decreases just before the price drop............................ 35

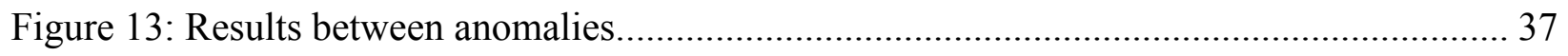

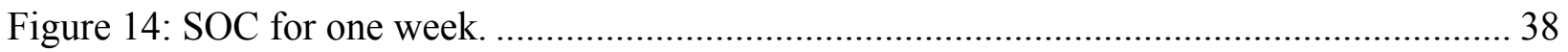




\section{LIST OF ABBREVIATIONS}

\begin{tabular}{|l|l|}
\hline Term & Abbreviation \\
\hline Real-time pricing & RTP \\
\hline Time-of-use & TOU \\
\hline Locational mean pricing & LMP \\
\hline State of charge & SOC \\
\hline Dynamic programming & DP \\
\hline Independent System Operators & ISO \\
\hline & \\
\hline
\end{tabular}




\section{INTRODUCTION}

\subsection{BACKGROUND}

Energy storage has long constituted a critical part of electricity distribution systems around the world. Supply of electricity must closely match the demand; if too little power is produced, large-scale blackouts can result, and if too much power is produced, power is curtailed [1]-[3]. Energy storage systems allow for low-cost base load power to be stored temporarily for use when demand and costs are high. This helps ensure that there will be sufficient supply in case of an unplanned equipment outage, and also that excess energy is not completely wasted [4]. Historically, grid-scale electrical storage has been provided by pumped hydro systems [5].

As intermittent renewable energy generation is added to the grid at consistently increasing rates, the role of energy storage becomes more important [1], [6]. The output of wind and solar installations can be intermittent depending upon weather conditions such as passing clouds and gusty winds [4], [7]-[9]. Energy storage with fast response time is helpful in mitigating the intermittency of these renewable electricity generators.

Battery storage for grid-scale applications has several key benefits that are important for supporting a grid with a high percentage of renewable energy generators [10]. Batteries can dispatch energy within seconds, not minutes or hours like some storage systems[1], [2]. They have a low self-discharge rate, so energy can be stored for a long period of time without much loss [2], [11]. Additionally, batteries are scalable to the application, and are not site dependent like pumped hydro or compressed air energy storage [2], [10]. Batteries also have some key drawbacks, which make them not cost effective at their current prices. In most grid-scale applications, high initial costs often more than offset any economic value batteries are able to 
achieve, while degradation over time reduces their capacity [12]. However, new developments and maturation of battery technology has driven prices down, and will lead to profitability in the near future [13]-[15].

A significant amount of research has been done to analyze the profitability of battery storage in particular applications, such as peak shaving for consumers [16], and renewables firming for intermittent energy generators [14], [17]. Additional research has been done into the feasibility of utilizing electric vehicle batteries for ancillary grid services [18]-[21]. Some of this research was conducted under RTP electricity tariffs, and some of it was conducted under TOU rates [22]. TOU tariffs are historically how electricity has been billed to large scale consumers; however, RTP is starting to become more common [23]. RTP can have several advantages over other pricing models; since consumers assume the real costs of electricity production and delivery at a given time, it allows them to make conscious decisions about reducing consumption when prices are high [24], [25]. This reduction of variability in the demand can lead to lower generation costs and emissions [24], [26].

Deploying battery storage for renewables firming in a RTP market could improve grid management due to their instantaneous response times, scalability and rapidly declining costs of batteries. While research has been conducted to analyze the cost-effectiveness of battery storage for particular applications, there is a gap in research that analyzes the most cost-effective placement of battery storage. This project will seek to model and quantify the economic benefit that can be realized from a battery storage system in a RTP market. It will compare various applications in order to determine if the economic value of the battery is independent of coupling the battery behind the gate with electrical generation or consumption. The results of this research 
will help determine if existing battery storage can be leveraged for grid services without a loss of renewables firming capability.

\subsection{Literature REVIEW}

The need for advanced energy storage, as intermittent renewable energy generation capability is increased, has been well documented [2], [4], [27]. The demand for widespread implementation of renewable energy is driven by environmental concerns, local legislation, and international treaties [2]. Storage technologies that can handle the intermittent nature of these energy sources are critical if the energy mix is to be dominated by non-dispatchable energy sources [2], [28]. Renewable energy that is stored can be used later, in times of less favorable conditions. This use of energy storage is called "renewables firming" [29].

Renewables firming is becoming a major concern as renewable energy reaches higher levels of penetration [4], [28]. Renewables firming allows energy to be provided with some degree of control and reliability during a given time period, even if the energy source is intermittent and undispatchable [29]. The combination of renewable energy generation and energy storage has proven effective in avoiding ramp rate penalties [30], that monetizes the costs associated with the speed at which renewables come online and offline [29]. While this synergistic effect results in quantifiable avoided costs, these ramp constraints do not apply in a RTP market [25].

Previous research has assumed that renewables firming is inherently beneficial, and that energy storage can add value to the renewable generation irrespective of the market parameters [28]. In some particular instances, synergistic effects have been observed [31]; however, the benefits are dependent on market conditions such as outage protection and TOU tariffs. Research has not been done to test if a synergistic relationship between renewable energy and energy 
storage exists in a RTP market. This project analyzes the economic benefit of battery storage in a renewables firming configuration to determine if the renewables firming battery contributes an increased value when compared to the case of a disaggregated battery.

As mentioned previously, batteries provide key advantages that are valuable to a grid that has high intermittent energy implementation. The rapidly declining costs of battery storage has been well documented, and will provide increasing opportunities for profitable operation of gridscale battery storage systems [13]-[15]. This project provides a comparison of battery configurations in order to analyze the economic benefit of battery storage relative to a disaggregated grid-connected battery, and does not seek to determine at what cost grid-scale battery storage will become profitable.

RTP tariffs can also improve the market potential for renewable energy generation [9], [25]. During times of high electricity production, consumers can increase their energy demand at low marginal cost. RTP can also reduce peak demand, resulting in a reduction of emissions [15]. This reduction of emissions is dependent on the energy source dominating in the region, and is reduced at higher levels of renewable implementation [24]. More markets are moving towards RTP in order to capture the true market volatility, and allow customers to shift their usage patterns to take advantage of lower prices [32]. Battery storage implemented in TOU pricing markets has been demonstrated to realize only limited economic gains, due to relatively small price differential [3], [15]. However, implementing battery storage in RTP markets may lead to more profitability due to increased price volatility [3].

This project uses a model of battery storage in a RTP market in order to determine if renewables firming has an inherent synergistic economic benefit, or if the economic value that can be derived from combining battery storage with renewable energy is simply the sum of its 
parts. Similarly, this project also analyzes a peak shaving application of battery storage to evaluate if the system yields additional value beyond a disaggregated grid-connected battery.

Based on this understanding of the literature, we can compose 3 research questions to guide this investigation.

\subsection{Research Questions}

1. Does there exist an economic benefit to coupling a battery storage system with intermittent electrical generation or manufacturing loads relative to a disaggregated grid-connected battery in a RTP market?

2. What are the primary drivers of economic benefit in a RTP market using grid-scale battery storage?

3. Which battery parameters can be optimized to maximize economic benefit of a battery storage system in a RTP market?

This thesis seeks to answer these research questions by developing a model to compare the economic benefits of coupled and disaggregated battery energy storage systems in RTP markets. 


\section{METHODS}

\subsection{OVERVIEW}

The purpose of this project was to determine the economic value that could be derived from a grid-scale battery in a three distinct cases, (1) connected to the grid independent of other generation or consumption, (2) connected behind the gate to solar power generation, and (3) connected "behind-the-meter" to a manufacturing plant. These three configurations represent the battery energy storage business cases of energy arbitrage, renewables firming, and peak shaving, respectively. A mathematical model was created to simulate each case. DP was utilized in order to determine the optimal control of the battery and the maximum economic benefit that can be derived from it. Because this project compares the economic benefit of the three configurations, an idealized battery was modeled.

\subsubsection{Case 1: Grid-Connected Battery in Pure Arbitrage Application}

The economic value of Case 1, a stand-alone grid-scale battery, was determined by modeling the system to maximize dollars as it participates in arbitrage in a RTP market. Figure 1 demonstrates the functionality of the battery. The system was modeled to only buy and sell electricity directly with the grid. It realizes value by buying when costs were low, and selling when costs were high. No exogenous electrical generation or consumption was modeled for the Case 1 system. This allowed the maximum economic value of the battery to be determined for a given set of parameters and RTP market datasets. 


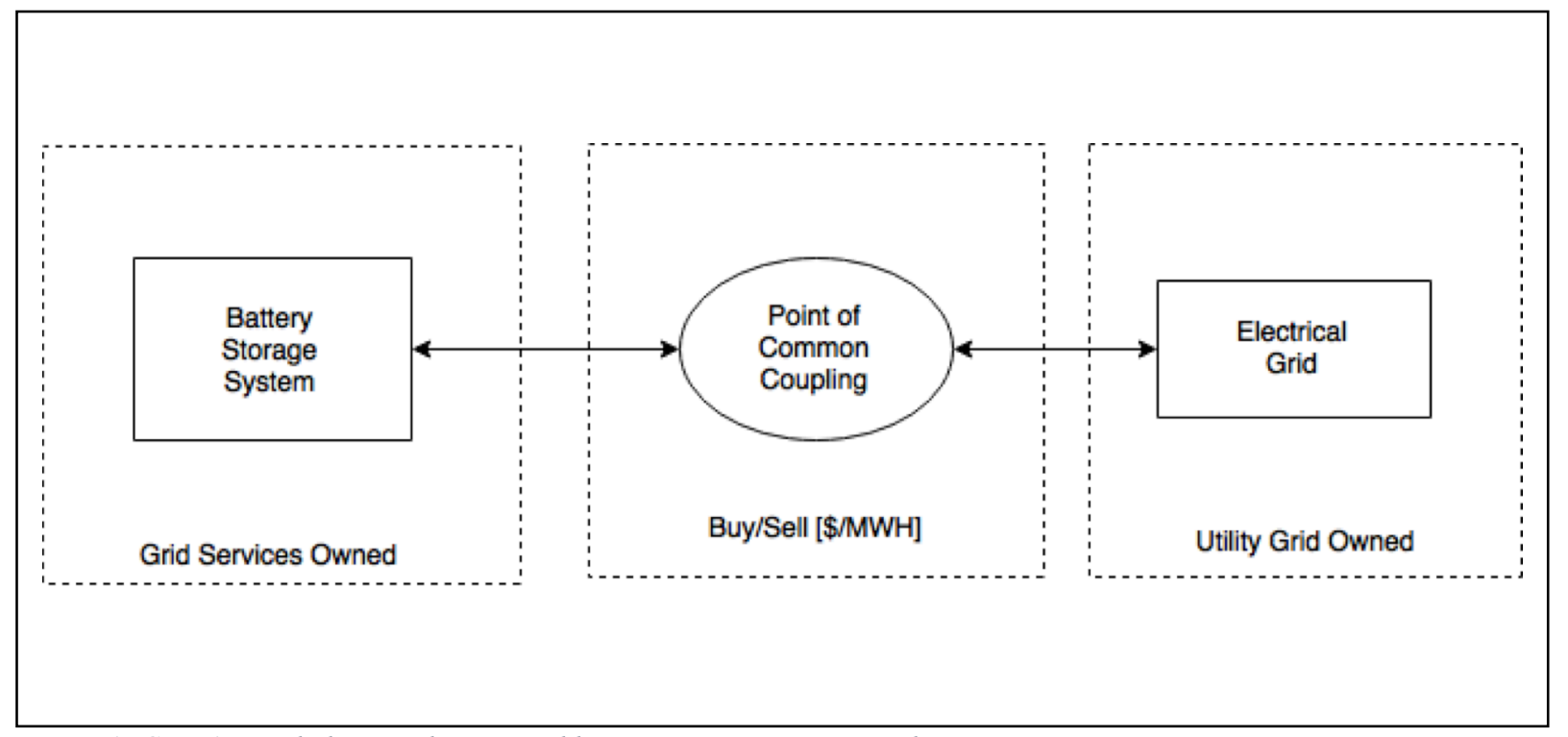

Figure 1: Case 1, stand alone grid-connected battery operating in pure arbitrage.

\subsubsection{Case 2: Grid-Connected Battery in Renewables Firming Application}

The system model for Case 2, renewables firming, was designed such that the grid-scale battery was connected to a solar energy generation facility. Figure 2 demonstrates the functionality of the renewables firming system. The battery was still modeled to participate in arbitrage, but could also supply the solar installation with power to run its auxiliary systems

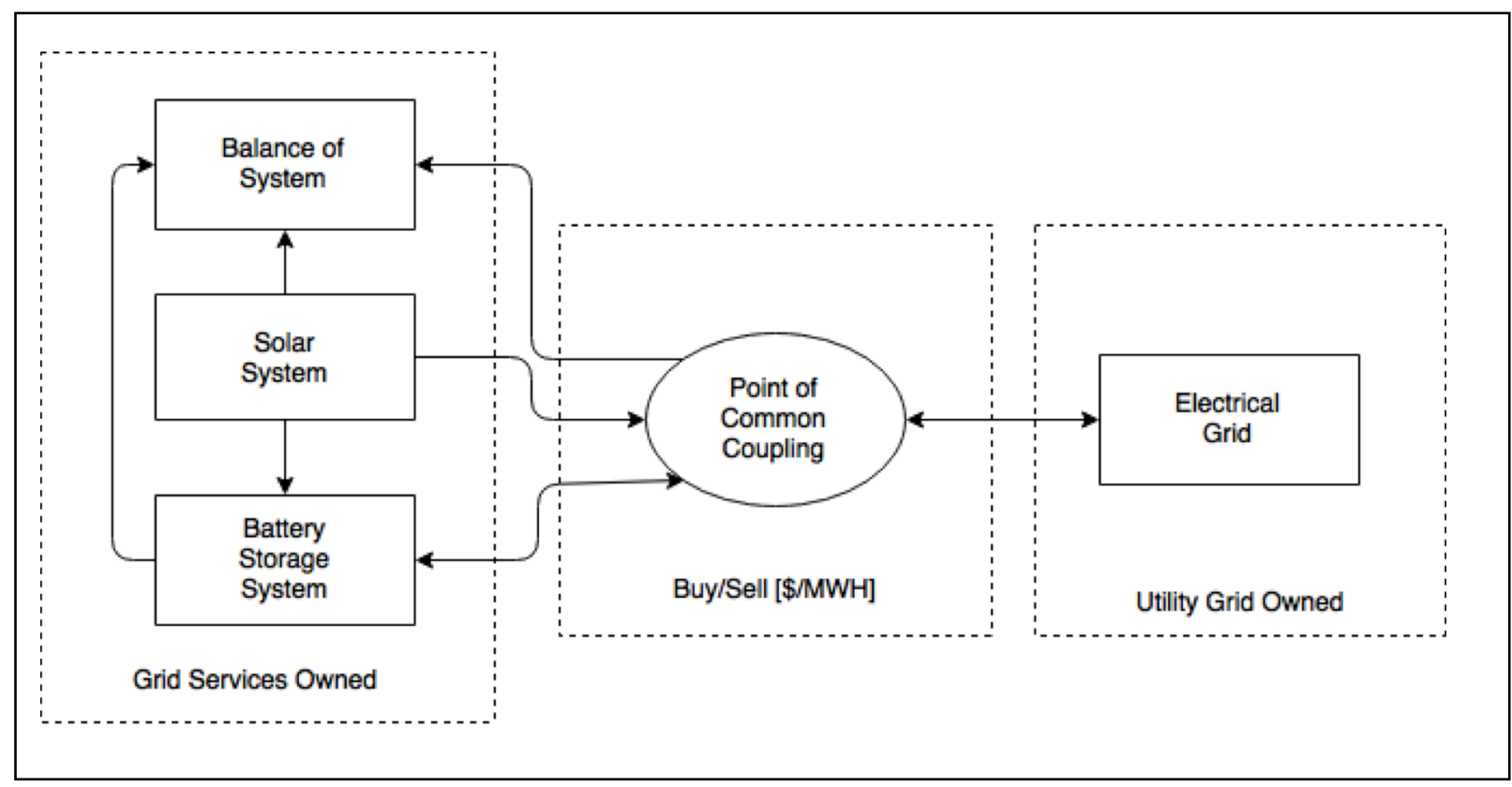

Figure 2: Case 2, solar array with grid-connected battery storage. 
during times of high pricing, or charge from the solar array during times of low pricing. The solar installation was also modeled to be able to buy and sell electricity directly from the grid depending on the price of electricity and the optimal control of the battery. For example, during times of high pricing while the solar array was outputting electricity, both the battery and the solar field would be able to sell electricity to the grid. In times of low pricing, when the solar installation required power for "balance of system system" loads, electricity would be purchased from the grid to both charge the battery and power the solar installation.

\subsubsection{Case 3: Grid-Connected Battery in Peak Shaving Application}

The system for Case 3, peak shaving, was modeled such that the grid-scale battery was connected "behind-the-meter" to a load of the manufacturing plant. Figure 3 demonstrates the functionality of the peak shaving configuration. Unlike the solar installation, the manufacturing plant exhibits electrical consumption only, not both consumption and production. The system was designed such that the battery could participate in arbitrage. The manufacturing plant could

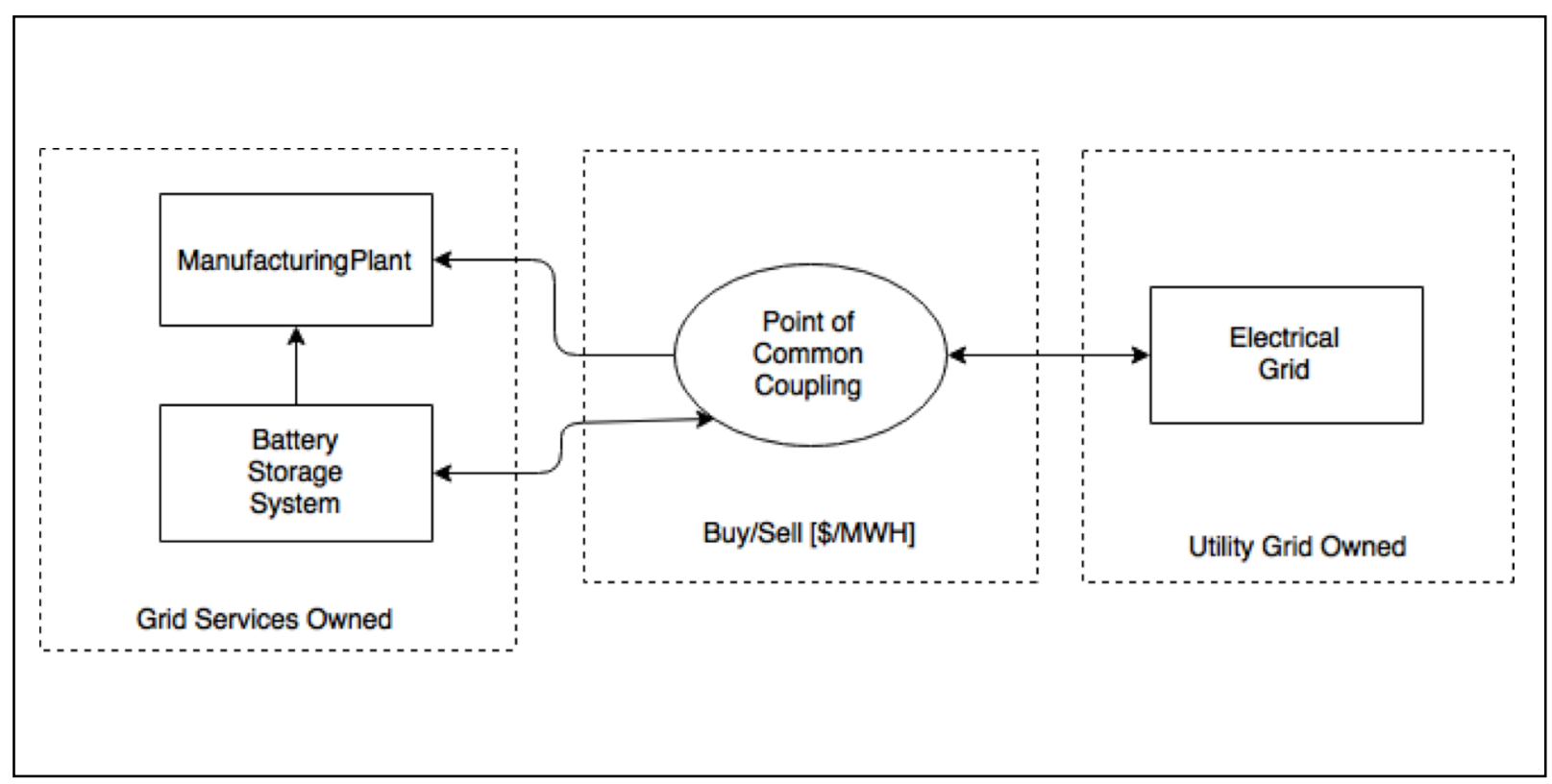

Figure 3 : Case 3, manufacturing plant with grid-connected battery storage 
buy electricity directly from the grid or draw power from the battery, depending upon the cost of electricity.

\subsection{Dynamic Programming}

The DP algorithm maximizes economic benefit throughout a given time range by controlling changes in the battery state of charge, and realizing value by buying or selling electricity at its real-time price. The time range is broken up into increments, each defined as a "stage", and the battery states of charge are each defined as a "state". DP allows for the determination of the optimal control at each state and stage. This allows for an optimal control sequence to be determined, based on a starting state and stage, which will maximize the economic benefit throughout the time period. Perfect forecasting is assumed so that the optimal control sequence yields the maximum total economic value that can be derived from the system.

The battery was modeled as a nonlinear dynamic system described by Equation 1, where time has been discretized as $k=1: N$.

\section{Equation 1:}

$$
S(k+1)=f(S(k), u(k), w(k))
$$

$S(k+1)$ represents the future SOC of the battery, and is dependent on the previous state of charge $S(k)$, the control input $u(k)$, which represents buying and selling electricity, and an exogenous input $w(k)$, which represents the generation or consumption connected to the battery. The discrete time intervals, or stages, were represented by $k$, and correspond to the 15 -minute pricing intervals. 
The DP algorithm optimizes the control $u(k)$ of the system, The control sequence is optimized by maximizing the objective function presented in Equation 2.

\section{Equation 2:}

$$
J=\sum_{K=1}^{N} g(S(k), u(k), w(k))
$$

The objective function $J$ is the summation of the economic benefit at each stage, $g(S(k)$, $u(k), w(k))$. The maximization of $J$ leads to the control sequence $u(k)$ which yields the optimal economic value.

\subsubsection{Value Function}

The value function, $g(S(k), u(k), w(k))$, defined for this study was applied at each state and stage, Equation 3.

\section{Equation 3:}

$g(S(k), u(k), w(k))[\$]=$ Energy $[\mathrm{MWh}] *$ Price $[\$ / \mathrm{MWh}]$

This was utilized to determine the optimal control, $u^{*}(k)$. The Energy term represents the total energy bought or sold at a given state and stage. This term was defined by Equation 4.

\section{Equation 4:}

$$
\begin{aligned}
& \text { Energy }[\mathrm{MWh}]=\left(\left(\text { Amps }[\mathrm{A}]^{*} \mathrm{~V}_{\mathrm{oc}}[\mathrm{V}]\right)-\left(\mathrm{R}_{\mathrm{int}}[\mathrm{Ohms}]^{*} A_{m p s^{2}}\right.\right. \\
& \left.\left.\left[\mathrm{A}^{2}\right]\right)\right) / 4,000,000[\mathrm{~W} / \mathrm{MW}-\mathrm{h}]+w(k)[\mathrm{MWh}]
\end{aligned}
$$

The $w(k)$ term represents the solar generation and manufacturing consumption for the given scenario. The Amps term represents the amount of current being charged to or discharged from the battery, and is defined by Equation 5 . 


\section{Equation 5:}

$$
\operatorname{Amps}[\mathrm{A}]=u(k)[\mathrm{MAh}]^{*}\left(1,000,000[\mathrm{Ah} / \mathrm{MAh}]^{* 4}[1 / \mathrm{hr}]\right)
$$

At each state and stage, the $g(S(k), u(k), w(k))$ term is calculated for every $u(k)$ option available, with positive values of $u(k)$ representing selling electricity, and negative values representing buying electricity. Then, the $u(k)$ option leading to the highest value will be saved as the optimal control for that particular state and stage. This allows the optimal path to be determined, from whatever starting state and stage are selected. The Total Value of the system, $\Sigma \mathrm{g}$, is then calculated using Equation 2.

\subsubsection{Algorithm Constraints}

The DP algorithm was subjected to several constraints on the SOC and the control. SOC was constrained such that the battery could not discharge below $0 \%$ SOC and could not charge beyond $100 \%$ SOC. In order to simulate a continuing process, the starting SOC for the simulation was set to $50 \%$. The value of the ending state is increasingly penalized the more it deviates from $50 \%$ state of charge, this is done by defining a quadratic end state penalty function, Equation 6.

\section{Equation 6:}

$$
\text { Penalty }=-100,000 *\left(S O C_{f}-0.5\right)^{2}
$$

This forces the DP algorithm to seek an end SOC close to $50 \%$ unless the price of electricity is sufficiently high or low to overcome the penalty. 
The control input $u(k)$, was constrained to operate between a minimum current and a maximum current, based on the $\mathrm{C}_{\text {rate }}$ of the simulation. Negative current represents charging, and positive current represents discharging.

\subsubsection{Idealized Battery}

The battery modeled for this simulation was an idealized case, operating at $100 \%$ coulombic efficiency and without degradation due to cycling. The internal resistance, or $\mathrm{R}_{\text {int }}(\mathrm{Ohms})$, was

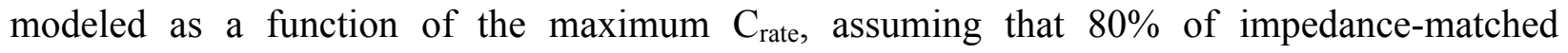
maximum power is available, Equation 7.

\section{Equation 7:}

$$
\mathrm{R}_{\text {int }}=\left(\mathrm{V}_{\mathrm{oc}} / 2[\mathrm{~V}]\right) *\left(1 / \mathrm{C}_{\text {rate }}[1 / \mathrm{hr}] * 1,000,000\right) *(0.8)
$$

This internal resistance term reduces the efficiency of the battery at high rates of charge and discharge. The open circuit voltage $\left(\mathrm{V}_{\mathrm{OC}}\right)$ that the battery model operated at was fixed at 480 Volts, and the battery capacity was fixed at 1 Mega Amp-Hour.

\subsection{DATA}

Data sets were acquired for the electricity pricing, the solar generation, and the manufacturing plant consumption. The data sets used in this project are all from real-world sources so as to allow for accurate reproduction of short and long term dynamics without approximation. The data is from various locations around the United States, which serves to reduce dependence on localized effects, such as outages and weather. Each data set spans an entire year, encompassing 366 days. 


\section{Pricing Data}

The RTP data was acquired from ISO New England ${ }^{1}$. It is comprised of 15 minute final nodal LMP data, and it was collected from December $14^{\text {th }}, 2015$ through December $13^{\text {th }}, 2016$. Because 2016 was a leap year, there are 366 days in the data set, each with 96 different price values. Prices are reported in units of $\$ / M W h$. Negative prices are possible, and do occur in the data set. Factors such as low demand and high supply can create short instances of negative pricing, which represent the utility paying customers to consume electricity. In this dataset in

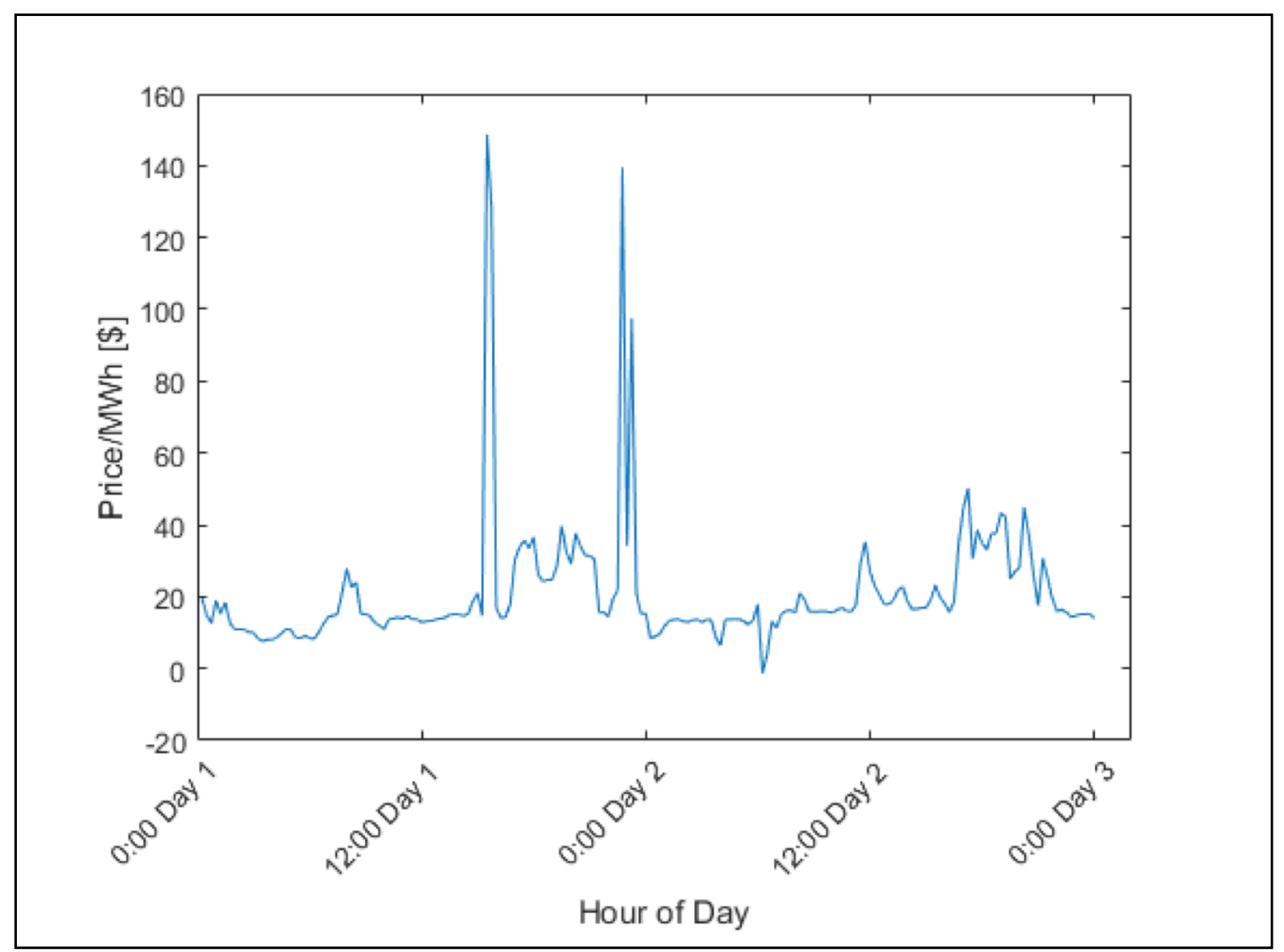

Figure 4: Sample of pricing data from December $14^{\text {th }}$, 2015 to December $15^{\text {th }}$, 2015. ISO New England 15minute final LMP.

particular, there are a number of price spikes that are short in duration. A sample day of RTP data can be seen in Figure 4.

${ }^{1}$ ISO New England final nodal fifteen-minute LMP data from historical and RTP database. Available from https://www.iso-ne.com 


\subsubsection{Solar Field Data}

The solar field data was from the Christman Field in Fort Collins, Colorado ${ }^{2}$. The solar installation contains two phases. Phase $\mathrm{I}$ is a $2 \mathrm{MW}$ multicrystalline silicone system that was completed in 2009. Phase II is a 3.3MW multicrystalline silicone system that was completed in 2010. The data was acquired through SunEdison, the company responsible for data acquisition of the system. It is comprised of 15 minute billable energy data in units of $\mathrm{kWh}$, collected from October $1^{\text {st }}, 2015$ through September $30^{\text {th }}, 2016$. Because 2016 was a leap year, this data also

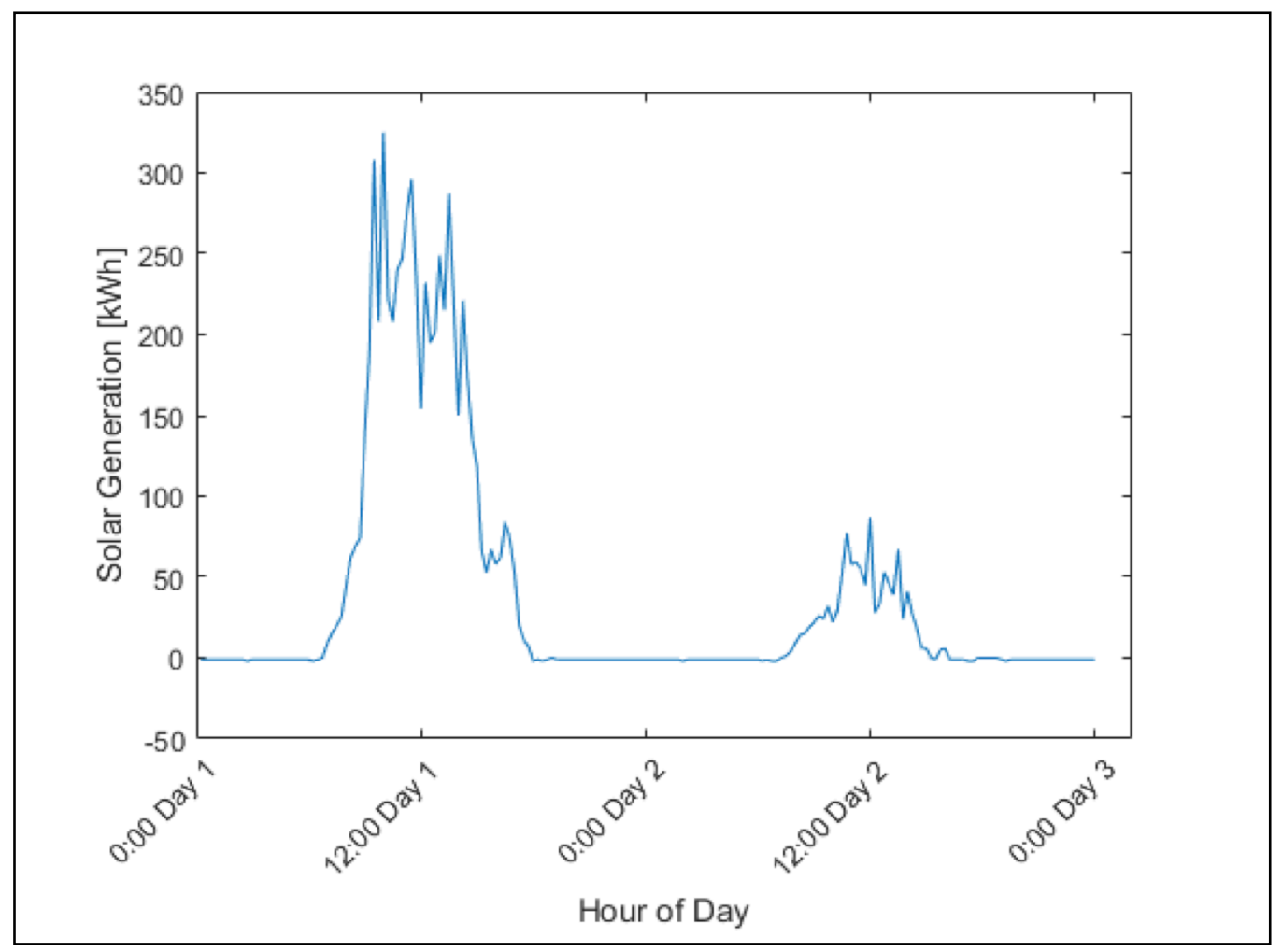

Figure 5: Sample solar data from October 1st, 2015 to October 2nd, 2015. Christman Field Phase 1.

contains 366 days of solar output. Negative output is common during the nighttime hours, and represents the energy required to run the auxiliary systems at the solar field. There are also times during which energy is neither produced nor consumed, and these represent times when the

${ }^{2}$ Christman Field Solar Data provided by SunEdison. 
system was offline. There are strong daily and seasonal effects present in this dataset which are a direct result of the earth's motion relative to the sun. A sample day of solar field data can be seen in Figure 5.

\subsubsection{Manufacturing Plant Data}

The manufacturing plant consumption data was acquired from ENERNOC's Open Data database ${ }^{3}$. This dataset in particular is from a light manufacturing plant in Chicago, Illinois. It is

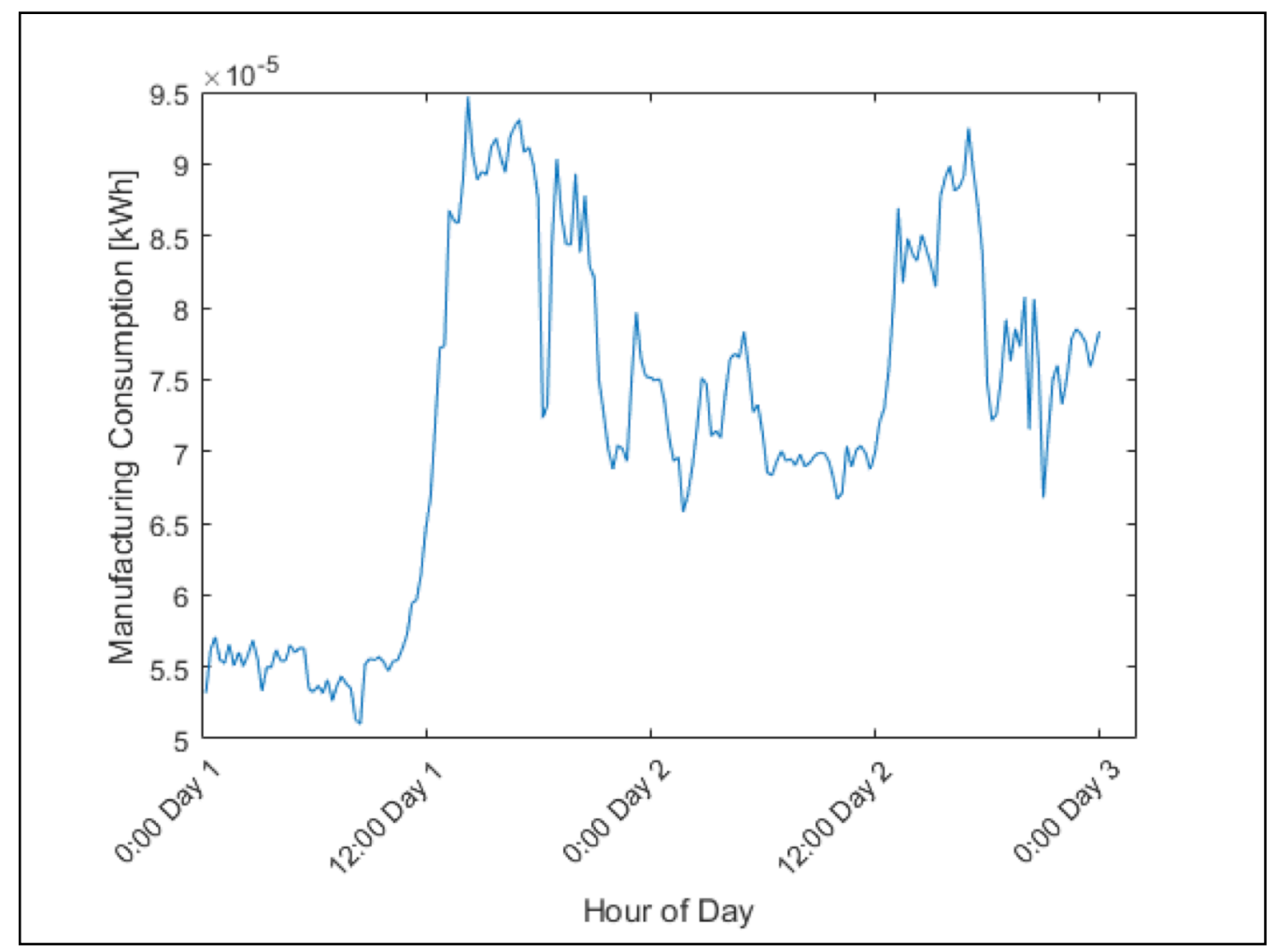

Figure 6: Sample of manufacturing plant data from January 3rd, 2012 to January 4th, 2012. ENERNOC Open Data.

comprised of 5 minute power draw in units of [kW]. To convert the data into a usable form, an average power draw over each 15 minute interval was determined. Then, the average power draw was divided by 4 [segments/hour] to determine the amount of energy consumed in the 15 minute period in units of $[\mathrm{kWh}]$. There is a strong seasonality to this dataset, as well as demand

${ }^{3}$ Manufacturing plant data is made available to the public by ENERNOC. Available from https://open-enernoc-data.s3.amazonaws.com/anon/index.html 
indicative of a 5-day workweek. A sample day of manufacturing plant consumption can be seen in Figure 6.

\subsection{Grid Convergence Study}

A grid convergence study was completed to ensure that the DP algorithm was converging on a robustly optimal answer. The total economic value was examined for various discretizations of battery states. Increasing the number of states also increases the number of control options available; this finer grid allows the DP algorithm to test more control options at each stage, leading to a more precise control sequence. The objective of the grid convergence study was to verify that the simulation successively converged on a single figure for economic benefit as the fineness of the battery's SOC grid was increased. If the program converges on an optimal value as the number of considered battery states is increased, then this optimal trajectory and optimal value can confidently be used as the solution.

Since batteries can have a diverse range of characteristics, this grid convergence study was conducted for several battery models, varying only the maximum $\mathrm{C}_{\text {rate. }}$. The maximum $\mathrm{C}_{\text {rate }}$ is the fraction of capacity that the battery can charge or discharge in a given hour. A battery with a maximum $\mathrm{C}_{\text {rate }}$ of 1.0 can fully charge or discharge in one hour. A battery with a maximum $\mathrm{C}_{\text {rate }}$ of 2.0 can fully charge or discharge in a half an hour. The grid convergence study was conducted for a total of 7 different $\mathrm{C}_{\text {rate }}$ values. The DP algorithm was conducted for 4 discretizations of available states of charge. Each battery has a minimum SOC value of $0 \%$ and a maximum SOC value of $100 \%$. Increasing the battery states simply increases the resolution of the energy states available. For example, the battery with 101 SOC has increments of $1 \%$ while the battery with 1001 SOC has increments of $0.1 \%$. The grid convergence study was run on ISO New England 
real-time price data for a single day, the $14^{\text {th }}$ of December, 2015. The results of this study are presented in section 3.5

\subsection{Case Comparison Simulations}

Once the grid convergence study demonstrated that the DP optimization was converging on a solution, the DP optimization was applied to a full year of real-time pricing data. $\mathrm{A} \mathrm{C}_{\text {rate }}$ of 1.0 was selected for comparing the three configurations, and 101 discrete states of charge were utilized. A summary of the relevant battery parameters is presented in Table 1.

Table 1: Battery Parameters used for the Baseline Scenario

\begin{tabular}{|c|c|c|}
\hline Battery Parameters & Value & Units \\
\hline Battery Capacity & $1,000,000$ & Amp Hours \\
\hline Open Circuit Voltage & 480 & Volts \\
\hline $\mathrm{C}_{\text {rate }}$ & 1 & $\begin{array}{c}\text { Fraction of charge per } \\
\text { hour }\end{array}$ \\
\hline $\begin{array}{c}\text { Internal Resistance at } \\
\mathrm{C}_{\text {rate }} \text { of } 1\left(\mathrm{R}_{\text {int }}\right)\end{array}$ & 192 & Micro-ohms \\
\hline SOC Discretization & 1 & $\%$ \\
\hline $\begin{array}{c}\text { Total Number of Charge } \\
\text { States }\end{array}$ & 101 & States \\
\hline
\end{tabular}

\subsection{Isolating Net VALUe OF BATtery}

In order to compare the three systems, the economic value of the battery storage system in Case 2 and Case 3 had to be isolated from the value of the total system. To do this, the total value of the solar generation and manufacturing plant consumption was calculated without energy storage systems connected to them. Then the value of the solar generation without storage was subtracted from Case 2, renewables firming, and the value of the manufacturing plant consumption without storage was subtracted from Case 3, peak-shaving. This process was used to determine if the total value each system was the sum of the value of its components, or if 
synergistic effects were present which increased the value of the system beyond the sum of the components.

\subsubsection{Solar Generation with no Storage}

To calculate the total value of the solar generation without storage, the generation was multiplied by the instantaneous price of electricity. This resulted in a figure which represented the total income that could be derived from the solar installation using the same RTP for the Case 1, Case 2, and Case 3 simulations. This figure was then subtracted from the total value derived from the renewables firming system (Case 2), in order to normalize value of Case 2 so that it could be compared to the total value of Case 1. Figure 7 illustrates the functionality of the solar system with no storage capability.

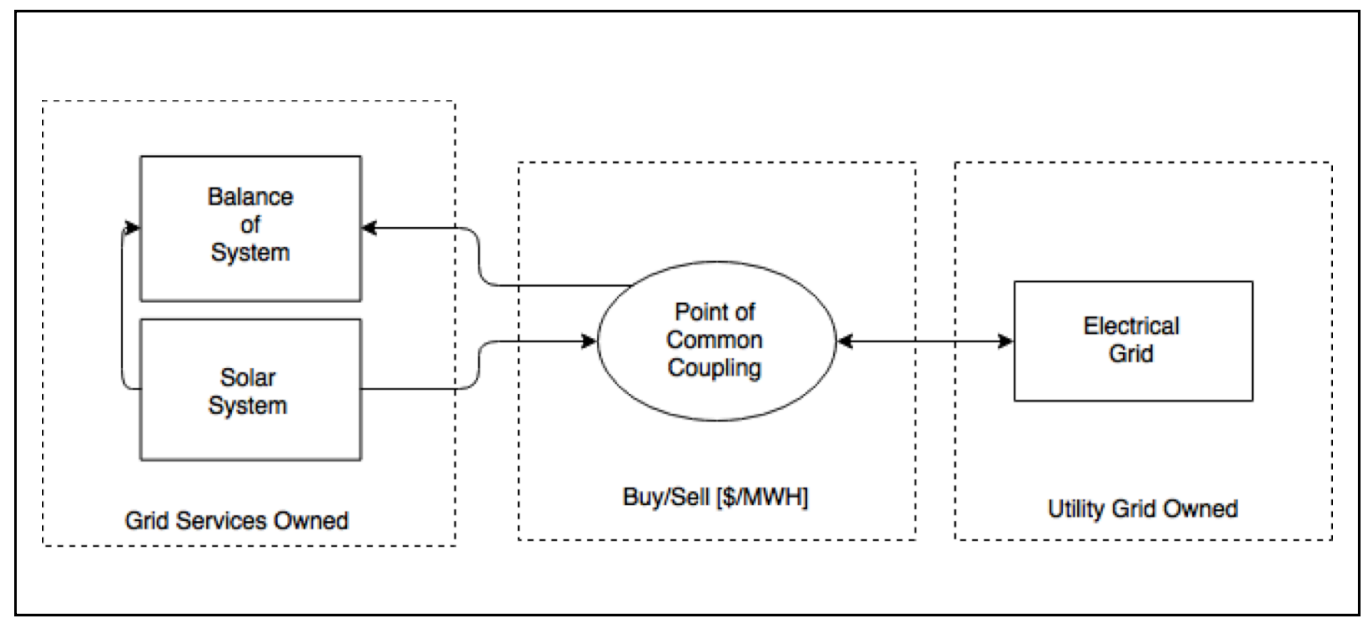

Figure 7: Configuration of solar field with no storage.

\subsubsection{Manufacturing Plant Consumption with no Storage}

To calculate the total value of the manufacturing plant consumption without storage, the consumption was multiplied by the instantaneous price of electricity. The result is a gross cost that would be incurred from operating the manufacturing plant using the same RTP for the Case 1, Case 2, and Case 3 simulations. This figure was then subtracted from the total value derived from the peak shaving system (Case 3), in order to normalize value of Case 3 so that it could be 
compared to the total value of Case 1 . Figure 8 demonstrates the structure of the manufacturing plant without storage capability.

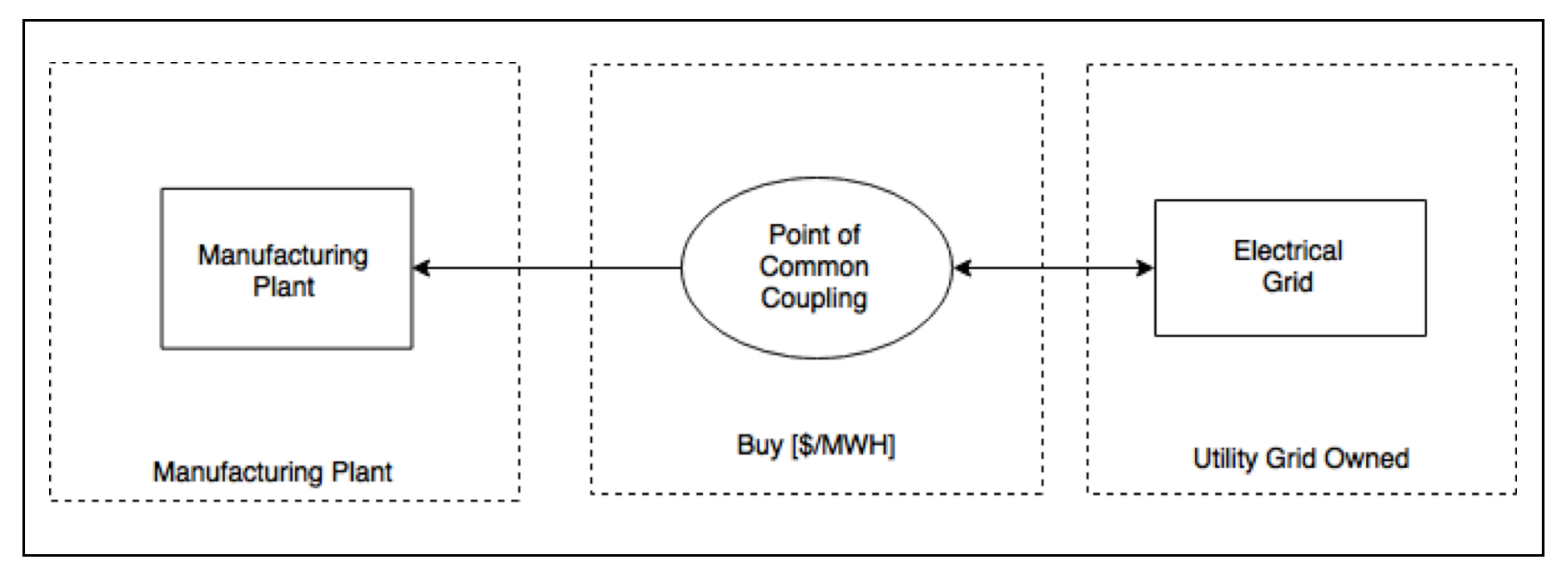

Figure 8: Configuration of manufacturing plant without storage.

\subsection{Simulation VARIATIONS}

In order to determine if the conclusions are robust to a wide variation in expected conditions, a computational design of experiments was performed. The simulation parameters, including pricing, solar generation, and manufacturing plant data were each modified for

Table 2: Summary of simulation variations.

\begin{tabular}{|c|c|c||}
\hline $\begin{array}{c}\text { Simulation } \\
\text { Number }\end{array}$ & Varied Parameter & Description \\
\hline 1 & None & Baseline scenario: Parameters in Table 1 \\
\hline 2 & VOC & Open circuit voltage reduced by half \\
\hline 3 & Capacity & Capacity doubled from 1MAh to $2 M A h$ \\
\hline 4 & Price Data & RTP values multiplied by a factor of 10 \\
\hline 5 & Solar Data & Solar data multiplied by a factor of 100 \\
\hline 6 & Manufacturing Data & Manufacturing data multiplied by a factor of 0.5 \\
\hline 7 & Seasonality & Data sets aligned to start on December $14 t h$ \\
\hline
\end{tabular}

different simulations. Additionally, the $\mathrm{V}_{\mathrm{OC}}$ was reduced by half, and capacity was doubled for other simulations. For each variation, the simulation was run for all three cases. A summary of all the simulation variations can be seen in Table 2 . 


\subsection{RESEARCH LIMITATIONS}

This research has several limitations, some of which are simplifying assumptions, and others are necessary in order to answer the research questions presented in section 1.2. To determine the maximum economic value that could be realized through coupling the battery system with electrical generation and consumption, perfect forecasting of pricing data had to be included in the simulation. Additionally, because this project compares a battery system in several configurations, several effects that occur during the operation of real-world batteries were neglected. These include degradation due to cycling, internal thermal effects and management, and losses due to depth of discharge. These effects would have real impacts on the economic value that can be generated through the battery storage system, but do not help determine if there is an economic case for coupling battery storage systems to loads in a RTP market. 


\section{RESULTS}

\subsection{OVERVIEW}

The results obtained from this project are separated into two categories, the grid convergence study and the comparison simulations. The grid convergence study provided the validation of convergence of the simulation results. The comparison simulations were conducted to examine the principles of renewables firming and peak shaving in an RTP market. These simulations included seven variations in order to determine if the results reveal a scenario dependent occurrence, or an underlying mathematical principle.

\subsection{Grid CONVERGENCE STUdy}

Table 3 presents the results of the grid convergence study. Twenty-eight simulations were conducted for twelve $\mathrm{C}_{\text {rate }}$ values and four levels of increasing SOC discretization. The results demonstrate convergence to a single Total Value $(\Sigma \mathrm{g})$ figure for each individual $\mathrm{C}_{\text {rate. }}$ This supports the simulation validation, as it shows convergence as a function of increased mesh refinement.

The results also reveal increasing economic benefit with higher $\mathrm{C}_{\text {rate. }}$. Each increase in $\mathrm{C}_{\text {rate }}$ corresponds to an increase in economic value that can be derived from the system. However, uniform increases in $\mathrm{C}_{\text {rate }}$ do not correspond to uniform increases in economic benefit. Increasing the $\mathrm{C}_{\text {rate }}$ from 1 to 2 increases the total value by approximately $85 \%$, while increasing $\mathrm{C}_{\text {rate }}$ from 3 to 4 increases the total value by $16 \%$. On the basis of the results, 101 states were choses for all future studies. 
Table 3: Grid convergence study results. Total value at varying C-rate and increasing refinement of battery SOC

\begin{tabular}{|c|c|c|c|c|c|c|}
\hline \multirow{2}{*}{$\mathbf{C}_{\text {rate }}$} & \multicolumn{7}{|c|}{ Number of States } \\
\cline { 2 - 7 } & $\mathbf{4 1}$ & $\mathbf{8 1}$ & $\mathbf{1 0 1}$ & $\mathbf{2 0 1}$ & $\mathbf{5 0 1}$ & $\mathbf{1 0 0 1}$ \\
\hline 0.04 & -- & -- & $\$ 1,863.43$ & $\$ 2,064.54$ & $\$ 2,116.83$ & $\mathbf{\$ 2 , 1 2 5 . 0 4}$ \\
\hline 0.4 & $\$ 17,010.00$ & $\$ 17,129.00$ & $\$ 17,143.27$ & $\$ 17,166.51$ & $\$ 17,172.28$ & $\mathbf{\$ 1 7 , 1 7 2 . 8 9}$ \\
\hline 1.0 & $\$ 37,847.00$ & $\$ 37,914.00$ & $\$ 37,920.56$ & $\$ 37,927.72$ & $\$ 37,930.38$ & $\mathbf{\$ 3 7 , 9 3 0 . 7 3}$ \\
\hline 2.0 & $\$ 70,022.00$ & $\$ 70,058.00$ & $\$ 70,063.24$ & $\$ 70,067.99$ & $\$ 70,069.67$ & $\mathbf{\$ 7 0 , 0 7 0 . 0 2}$ \\
\hline 3.0 & $\$ 91,664.00$ & $\$ 91,683.00$ & $\$ 91,688.03$ & $\$ 91,689.87$ & $\$ 91,691.30$ & $\mathbf{\$ 9 1 , 6 9 1 . 4 1}$ \\
\hline 4.0 & $\$ 106,263.32$ & $\$ 106,273.79$ & $\$ 106,272.72$ & $\$ 106,277.02$ & $\$ 106,277.99$ & $\mathbf{\$ 1 0 6 , 2 7 8 . 2 5}$ \\
\hline 10.0 & $\$ 150,033.45$ & $\$ 150,042.48$ & $\$ 150,045.00$ & $\$ 150,045.56$ & $\$ 150,046.09$ & $\mathbf{\$ 1 5 0 , 0 4 6 . 1 2}$ \\
\hline
\end{tabular}

\subsection{Results of Case Comparison Simulations}

In addition to the Total Value $(\Sigma g)$, the result of each simulation also includes the optimal control sequence, and the resulting optimal SOC sequence, for each possible state, for all times,
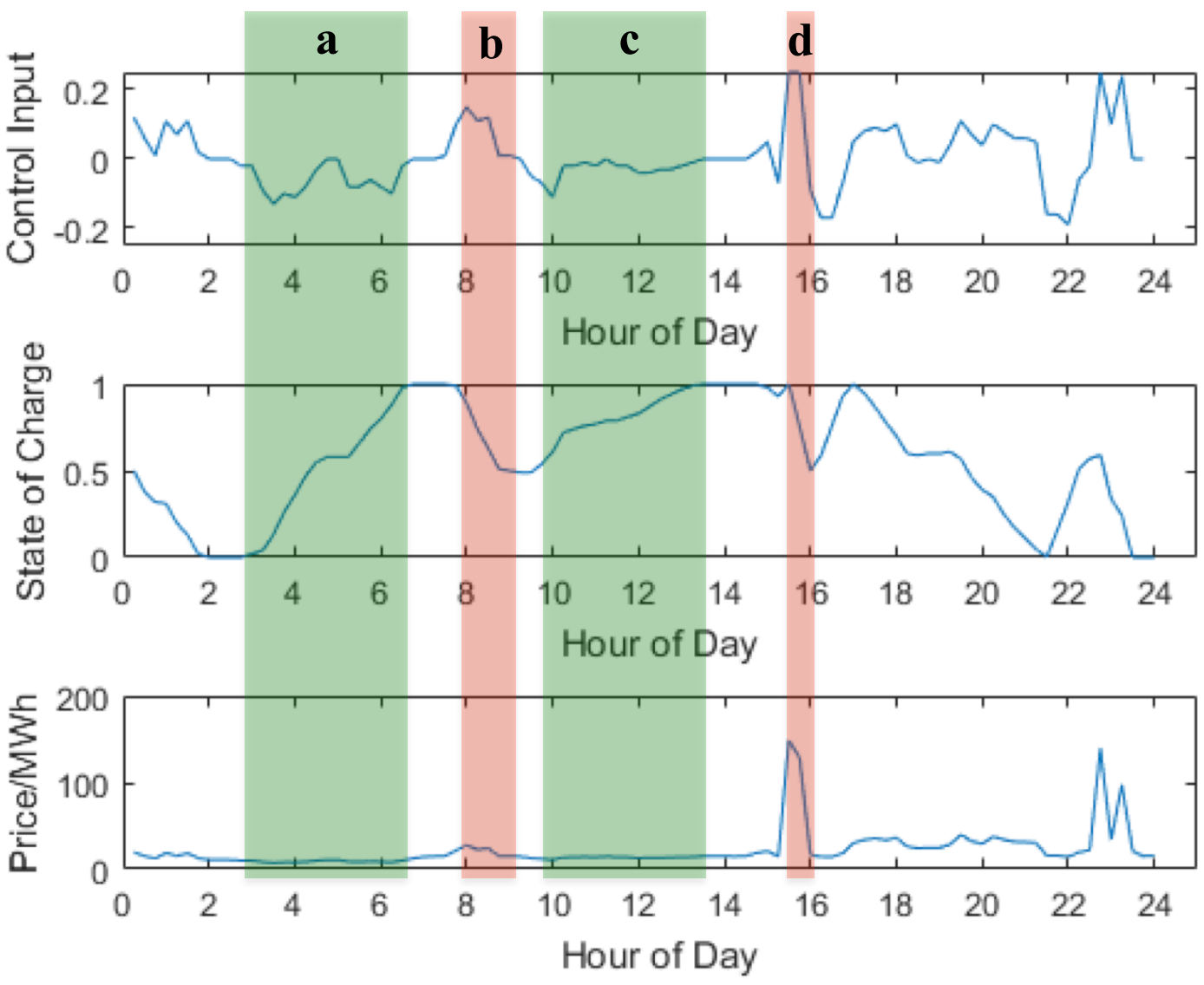

Figure 9: Example results showing battery function over a single day. Control sequence, SOC and Price are shown. 
for the entire year. Figure 9 illustrates the optimal control sequence, state of charge, and the price of electricity for an example time period. As described in Eqn 5, positive values of control correspond to the selling of electricity (highlighted in red), while negative values of control correspond to buying electricity (highlighted in green). Section A shows a time of relatively low, stable pricing, which the algorithm exploits through buying electricity to prepare for the price spike in section B. Section $\mathbf{C}$ similarly increases the SOC at a steady rate, until reaching section D, where a pricing anomaly results in a maximum selling of energy, and a rapidly decreasing SOC. The results of each year-long simulation are presented in the following subsections.

\subsubsection{Simulation 1: Baseline Scenario}

Specific to the baseline scenario, the value of the solar generation without storage and the total value of the manufacturing plant consumption without storage were determined based on simulation. No optimization was required to calculate these values. Table 4 presents these figures, which are required to calculate the net value of energy storage as described in section 2.6.

Table 4: Total value of the solar generation and manufacturing consumption without storage capabilities.

\begin{tabular}{|c|c|}
\hline \multicolumn{2}{|c|}{ Total Value of Solar Field and Manufacturing Plant without Storage } \\
\hline System & Value \\
\hline Solar Generation with no Storage & $\$ 99,784$ \\
\hline Manufacturing Consumption with no Storage & $-\$ 72,779$ \\
\hline
\end{tabular}

Table 5 demonstrates the economic value of each component of each system. Because Case 1 represents the stand-alone battery, the net value of the battery is equal to the total value of the system. In Case 2, the battery was connected to a solar array. When the value of the solar generation without storage was subtracted from the total system value, the net value of the 
battery was the same as Case 1. This principle is exhibited again in Case 3. When the value of the manufacturing plant consumption was subtracted from the total system value, the net value of

Table 5: Economic analysis of simulation 1. The total value of the system is presented for each case, along with the net value of the battery.

\begin{tabular}{|c|c|c|c|c|}
\hline \multirow{2}{*}{ Configuration } & \multicolumn{4}{|c|}{ Economic Value of Components: Simulation 1 } \\
\cline { 2 - 5 } & $\begin{array}{c}\text { Value of } \\
\text { System }\end{array}$ & $\begin{array}{c}\text { Value of Solar } \\
\text { Generation }\end{array}$ & $\begin{array}{c}\text { Value of } \\
\text { Manufacturing } \\
\text { Consumption }\end{array}$ & $\begin{array}{c}\text { Net Value of } \\
\text { Battery }\end{array}$ \\
\hline $\begin{array}{c}\text { Case 1: Pure } \\
\text { Arbitrage }\end{array}$ & $\$ 13,765,001$ & $\$ 0$ & $\$ 0$ & $\mathbf{\$ 1 3 , 7 6 5 , 0 0 1}$ \\
\hline $\begin{array}{c}\text { Case 2: Renewables } \\
\text { Firming }\end{array}$ & $\$ 13,864,785$ & $\$ 99,784$ & $\$ 0$ & $\mathbf{\$ 1 3 , 7 6 5 , 0 0 1}$ \\
\hline $\begin{array}{c}\text { Case 3: Peak } \\
\text { Shaving }\end{array}$ & $\$ 13,692,222$ & $\$ 0$ & $-\$ 72,779$ & $\mathbf{\$ 1 3 , 7 6 5 , 0 0 1}$ \\
\hline
\end{tabular}

the battery again matches Case 1 . For each case, the battery contributes the exact same value, and the total value of the system is simply the sum of the values of the system components.

\subsubsection{Simulation 2: $V_{\text {OC }}$ Variation}

Simulation 2 consisted of the same parameters as the baseline scenario with the exception of the open circuit voltage. The $\mathrm{V}_{\mathrm{OC}}$ was reduced by half, to a value of 240 Volts. Table 6 demonstrates the effects that this had on the total economic value of the systems. The value of the battery was

Table 6: Economic analysis of simulation 2. The total value of the system is presented for each case, along with the net value of the battery.

\begin{tabular}{|c|c|c|c|c|}
\hline \multirow{2}{*}{ Configuration } & \multicolumn{4}{|c|}{ Economic Value of Components: Simulation 2 } \\
\cline { 2 - 5 } & $\begin{array}{c}\text { Value of } \\
\text { System }\end{array}$ & $\begin{array}{c}\text { Value of Solar } \\
\text { Generation }\end{array}$ & $\begin{array}{c}\text { Value of } \\
\text { Manufacturing } \\
\text { Consumption }\end{array}$ & $\begin{array}{c}\text { Net Value of } \\
\text { Battery }\end{array}$ \\
\hline $\begin{array}{c}\text { Case 1: Pure } \\
\text { Arbitrage }\end{array}$ & $\$ 6,882,501$ & $\$ 0$ & $\$ 0$ & $\$ \mathbf{6 , 8 8 2 , 5 0 1}$ \\
\hline $\begin{array}{c}\text { Case 2: Renewables } \\
\text { Firming }\end{array}$ & $\$ 6,982,285$ & $\$ 99,784$ & $\$ 0$ & $\mathbf{\$ 6 , 8 8 2 , 5 0 1}$ \\
\hline $\begin{array}{c}\text { Case 3: Peak } \\
\text { Shaving }\end{array}$ & $\$ 6,809,722$ & $\$ 0$ & $-\$ 72,779$ & $\mathbf{\$ 6 , 8 8 2 , 5 0 1}$ \\
\hline
\end{tabular}


reduced by half, directly proportional to the $\mathrm{V}_{\mathrm{OC}}$. This is because as the power being charge or discharged from the battery is calculated using Equation 4, where the power is the product of the Amps and $\mathrm{V}_{\mathrm{OC}}$. Because the $\mathrm{V}_{\mathrm{OC}}$ was reduced by a factor of 2, the power that the system is able to charge or discharge is also reduced by a factor of 2 . The net value of the battery was equivalent for each of the three cases, indicating again that the total value of the system is equal to the sum of the individual components.

\subsubsection{Simulation 3: Capacity Variation}

In simulation 3, the capacity of the battery was doubled from $1 \mathrm{MAh}$ to $2 \mathrm{MAh}$. The other system parameters were held constant from the baseline scenario. Table 7 shows that the value of the system is approximately twice that of the baseline scenario. Because the $\mathrm{C}_{\text {rate }}$ was held constant, the $\mathrm{R}_{\text {int }}$ was reduced for the higher capacity battery, leading to less energy loss as the battery charges and discharges. This led to a battery total value of slightly more than double that of the baseline scenario. The results also reaffirms the findings of the other simulations, in that the net value of the battery is equivalent for all three cases.

Table 7: Economic analysis of simulation 3. The total value of the system is presented for each case, along with the net value of the battery.

\begin{tabular}{|c|c|c|c|c|}
\hline \multirow{2}{*}{ Configuration } & \multicolumn{4}{|c|}{ Economic Value of Components: Simulation 3 } \\
\cline { 2 - 5 } & $\begin{array}{c}\text { Value of } \\
\text { System }\end{array}$ & $\begin{array}{c}\text { Value of Solar } \\
\text { Generation }\end{array}$ & $\begin{array}{c}\text { Value of } \\
\text { Manufacturing } \\
\text { Consumption }\end{array}$ & $\begin{array}{c}\text { Net Value of } \\
\text { Battery }\end{array}$ \\
\hline $\begin{array}{c}\text { Case 1: Pure } \\
\text { Arbitrage }\end{array}$ & $\$ 27,530,003$ & $\$ 0$ & $\$ 0$ & $\mathbf{\$ 2 7 , 5 3 0 , 0 0 3}$ \\
\hline $\begin{array}{c}\text { Case 2: Renewables } \\
\text { Firming }\end{array}$ & $\$ 27,629,787$ & $\$ 99,784$ & $\$ 0$ & $\mathbf{\$ 2 7 , 5 3 0 , 0 0 3}$ \\
\hline $\begin{array}{c}\text { Case 3: Peak } \\
\text { Shaving }\end{array}$ & $\$ 27,457,224$ & $\$ 0$ & $-\$ 72,779$ & $\mathbf{\$ 2 7 , 5 3 0 , 0 0 3}$ \\
\hline
\end{tabular}




\subsubsection{Simulation 4: Price Data Variation}

Simulation 4 consisted of the same battery parameters as the baseline scenario, but the RTP data was multiplied by a factor of 10 . This had the effect of increasing the pricing variability; the standard deviation of the original pricing data was found to be 18.27 while the standard deviation of the pricing data multiplied by 10 was found to be 182.7 . The average price of electricity also shifted from $\$ 21 / \mathrm{MWh}$ to $\$ 210 / \mathrm{MWh}$. Table 8 illustrates the effect that increased price variability has on arbitrage. The net value of the battery is 10 times higher than the basic case. Because arbitrage takes advantage of pricing differentials, higher price variability will lead to more economic value generated through arbitrage. Conversely, if price volatility were to be reduced by a factor of 10 , a reduction of economic value would be expected. The net value of the battery is again consistent throughout the three cases. This indicates that the pricing affects the battery's economic value consistently across the three cases.

Table 8: Economic analysis of simulation 4. The total value of the system is presented for each case, along with the net value of the battery.

\begin{tabular}{|c|c|c|c|c|}
\hline \multirow{2}{*}{ Configuration } & \multicolumn{3}{|c|}{ Economic Value of Components: Simulation $\mathbf{4}$} \\
\cline { 2 - 5 } & $\begin{array}{c}\text { Value of } \\
\text { System }\end{array}$ & $\begin{array}{c}\text { Value of Solar } \\
\text { Generation }\end{array}$ & $\begin{array}{c}\text { Value of } \\
\text { Manufacturing } \\
\text { Consumption }\end{array}$ & $\begin{array}{c}\text { Net Value of } \\
\text { Battery }\end{array}$ \\
\hline $\begin{array}{c}\text { Case 1: Pure } \\
\text { Arbitrage }\end{array}$ & $\$ 137,650,146$ & $\$ 0$ & $\$ 0$ & $\mathbf{\$ 1 3 7 , 6 5 0 , 1 4 6}$ \\
\hline $\begin{array}{c}\text { Case 2: Renewables } \\
\text { Firming }\end{array}$ & $\$ 138,647,987$ & $\$ 997,841$ & $\$ 0$ & $\mathbf{\$ 1 3 7 , 6 5 0 , 1 4 6}$ \\
\hline $\begin{array}{c}\text { Case 3: Peak } \\
\text { Shaving }\end{array}$ & $\$ 136,922,359$ & $\$ 0$ & $-\$ 727,787$ & $\mathbf{\$ 1 3 7 , 6 5 0 , 1 4 6}$ \\
\hline
\end{tabular}




\subsubsection{Simulation 5: Solar Data Variation}

In simulation 5, the solar generation was multiplied by a factor of 100, effectively scaling up the solar field from $2 \mathrm{MW}$ to $200 \mathrm{MW}$. The other system parameters were held constant with the baseline scenario. Table 9 demonstrates that the value of the solar generation increases by a factor of 1000 , to $\$ 99,784,109$, but that this has no effect on the value of the battery. The net value of the battery in each case is exactly the same as scenario 1 . This indicates that the scale of the solar plant connected to a battery does not influence the economic value that can be derived from that battery.

Table 9: Economic analysis of simulation 5. The total value of the system is presented for each case, along with the net value of the battery.

\begin{tabular}{|c|c|c|c|c|}
\hline \multirow[b]{2}{*}{ Configuration } & \multicolumn{4}{|c|}{ Economic Value of Components: Simulation 5} \\
\hline & $\begin{array}{l}\text { Value of } \\
\text { System }\end{array}$ & $\begin{array}{c}\text { Value of Solar } \\
\text { Generation }\end{array}$ & $\begin{array}{c}\text { Value of } \\
\text { Manufacturing } \\
\text { Consumption }\end{array}$ & $\begin{array}{c}\text { Net Value of } \\
\text { Battery }\end{array}$ \\
\hline $\begin{array}{l}\text { Case 1: Pure } \\
\text { Arbitrage }\end{array}$ & $\$ 13,765,001$ & $\$ 0$ & $\$ 0$ & $\$ 13,765,001$ \\
\hline $\begin{array}{c}\text { Case } 2 \text { : Renewables } \\
\text { Firming }\end{array}$ & $\$ 23,743,412$ & $\$ 9,978,411$ & $\$ 0$ & $\$ 13,765,001$ \\
\hline $\begin{array}{l}\text { Case 3: Peak } \\
\text { Shaving }\end{array}$ & $\$ 13,692,222$ & $\$ 0$ & $-\$ 72,779$ & $\$ 13,765,001$ \\
\hline
\end{tabular}

\subsubsection{Simulation 6: Manufacturing Data Variation}

In simulation 6 , the manufacturing consumption data was multiplied by a factor of 0.5 while all of the other parameters were held constant with the baseline scenario. This effectively reduced the manufacturing plant consumption by half. Table 10 demonstrates the decrease in manufacturing cost, along with the resulting value of the case 3 system. When the value of the battery is isolated, the resulting net battery value is equal across all three cases. 
Table 10: Economic analysis of simulation 6. The total value of the system is presented for each case, along with the net value of the battery.

\begin{tabular}{|c|c|c|c|c|}
\hline \multirow{2}{*}{ Configuration } & \multicolumn{3}{|c|}{ Economic Value of Components: Simulation $\mathbf{6}$} \\
\cline { 2 - 5 } & $\begin{array}{c}\text { Value of } \\
\text { System }\end{array}$ & $\begin{array}{c}\text { Value of Solar } \\
\text { Generation }\end{array}$ & $\begin{array}{c}\text { Value of } \\
\text { Manufacturing } \\
\text { Consumption }\end{array}$ & $\begin{array}{c}\text { Net Value of } \\
\text { Battery }\end{array}$ \\
\hline $\begin{array}{c}\text { Case 1: Pure } \\
\text { Arbitrage }\end{array}$ & $\$ 13,765,001$ & $\$ 0$ & $\$ 0$ & $\$ \mathbf{\$ 1 3 , 7 6 5 , 0 0 1}$ \\
\hline $\begin{array}{c}\text { Case 2: Renewables } \\
\text { Firming }\end{array}$ & $\$ 13,864,785$ & $\$ 99,784$ & $\$ 0$ & $\mathbf{\$ 1 3 , 7 6 5 , 0 0 1}$ \\
\hline $\begin{array}{c}\text { Case 3: Peak } \\
\text { Shaving }\end{array}$ & $\$ 13,728,612$ & $\$ 0$ & $-36,389$ & $\mathbf{\$ 1 3 , 7 6 5 , 0 0 1}$ \\
\hline
\end{tabular}

\subsubsection{Simulation 7: Seasonality Variation}

In simulation 7, the pricing, solar and manufacturing data sets are seasonally aligned. This means that each was adjusted to begin on the same day as the pricing data, December $14^{\text {th }}$. Table 11 demonstrates that while this had some effect on the value of the solar and manufacturing total value, it did not alter the value of the battery. Changes in the generation and consumption value are caused by new electrical prices as a result of shifting the buying and selling of the energy. Despite this, the net value of the battery remains the same in all three cases.

Table 11: Economic analysis of simulation 7. The total value of the system is presented for each case, along with the net value of the battery.

\begin{tabular}{|c|c|c|c|c|}
\hline \multirow{2}{*}{ Configuration } & \multicolumn{4}{|c|}{ Economic Value of Components: Simulation 7} \\
\cline { 2 - 5 } & $\begin{array}{c}\text { Value of } \\
\text { System }\end{array}$ & $\begin{array}{c}\text { Value of Solar } \\
\text { Generation }\end{array}$ & $\begin{array}{c}\text { Value of } \\
\text { Manufacturing } \\
\text { Consumption }\end{array}$ & $\begin{array}{c}\text { Net Value of } \\
\text { Battery }\end{array}$ \\
\hline $\begin{array}{c}\text { Case 1: Pure } \\
\text { Arbitrage }\end{array}$ & $\$ 13,765,001$ & $\$ 0$ & $\$ 0$ & $\$ 13,765,001$ \\
\hline $\begin{array}{c}\text { Case 2: Renewables } \\
\text { Firming }\end{array}$ & $\$ 13,858,999$ & $\$ 93,998$ & $\$ 0$ & $\$ \mathbf{1 3 , 7 6 5 , 0 0 1}$ \\
\hline $\begin{array}{c}\text { Case 3: Peak } \\
\text { Shaving }\end{array}$ & $\$ 13,692,222$ & $\$ 0$ & $-\$ 72,779$ & $\mathbf{\$ 1 3 , 7 6 5 , 0 0 1}$ \\
\hline
\end{tabular}




\section{DISCUSSION}

\subsection{Grid Convergence Study}

The grid convergence study demonstrated decreasing relative error as the number of battery SOC was increased. Table 12 shows the relative error for the grid convergence study. In addition to decreasing relative error with respect to a finer SOC resolution, the relative error decreases as $\mathrm{C}_{\text {rate }}$ increases. This is a result of the increased battery capabilities. As the $\mathrm{C}_{\text {rate }}$ is increased, the battery is able to find more value through arbitrage, and further refinement of the SOC has less effect on that value.

Table 12: Relative error of the grid convergence study.

\begin{tabular}{|c|c|c|c|c|c|}
\hline \multirow{2}{*}{$\mathbf{C}_{\text {rate }}$} & \multicolumn{5}{|c|}{ Relative Error for Increasing Number of States } \\
\cline { 2 - 7 } & $\mathbf{4 1}$ to $\mathbf{8 1}$ & $\mathbf{8 1}$ to $\mathbf{1 0 1}$ & $\mathbf{1 0 1}$ to $\mathbf{2 0 1}$ & $\mathbf{2 0 1}$ to $\mathbf{5 0 1}$ & $\mathbf{5 0 1}$ to 1001 \\
\hline 0.04 & -- & -- & $9.74 \mathrm{E}-02$ & $2.47 \mathrm{E}-02$ & $3.86 \mathrm{E}-03$ \\
\hline 0.4 & $6.95 \mathrm{E}-03$ & $8.32 \mathrm{E}-04$ & $1.35 \mathrm{E}-03$ & $3.36 \mathrm{E}-04$ & $3.55 \mathrm{E}-05$ \\
\hline 1.0 & $1.77 \mathrm{E}-03$ & $1.73 \mathrm{E}-04$ & $1.89 \mathrm{E}-04$ & $7.01 \mathrm{E}-05$ & $9.23 \mathrm{E}-06$ \\
\hline 2.0 & $5.14 \mathrm{E}-04$ & $7.48 \mathrm{E}-05$ & $6.78 \mathrm{E}-05$ & $2.40 \mathrm{E}-05$ & $5.00 \mathrm{E}-06$ \\
\hline 3.0 & $2.07 \mathrm{E}-04$ & $5.49 \mathrm{E}-05$ & $2.01 \mathrm{E}-05$ & $1.56 \mathrm{E}-05$ & $1.20 \mathrm{E}-06$ \\
\hline 4.0 & $9.85 \mathrm{E}-05$ & $1.01 \mathrm{E}-05$ & $4.05 \mathrm{E}-05$ & $9.13 \mathrm{E}-06$ & $2.45 \mathrm{E}-06$ \\
\hline 10.0 & $6.02 \mathrm{E}-05$ & $1.68 \mathrm{E}-05$ & $9.74 \mathrm{E}-02$ & $2.47 \mathrm{E}-02$ & $3.86 \mathrm{E}-03$ \\
\hline
\end{tabular}

This fact is more clearly demonstrated in Figure 10 by the way that the slope of the graph decreases as $\mathrm{C}_{\text {rate }}$ increases. Increasing the $\mathrm{C}_{\text {rate }}$ of the battery allows more of the battery capacity to be charged and discharged in a given stage, which leads to higher total value through simple 
arbitrage. At a $\mathrm{C}_{\text {rate }}$ of 4 , the battery can fully charge or discharge in a single 15 minute increment. Because the pricing data is also in increments of 15 minutes, any increase in $\mathrm{C}_{\text {rate }}$ above 4 does not enable additional value through arbitrage. The increase in total value at $\mathrm{C}_{\text {rate }}$ higher than 4 is only a result of the decrease in internal resistance, and the corresponding increase in battery energetic efficiency.

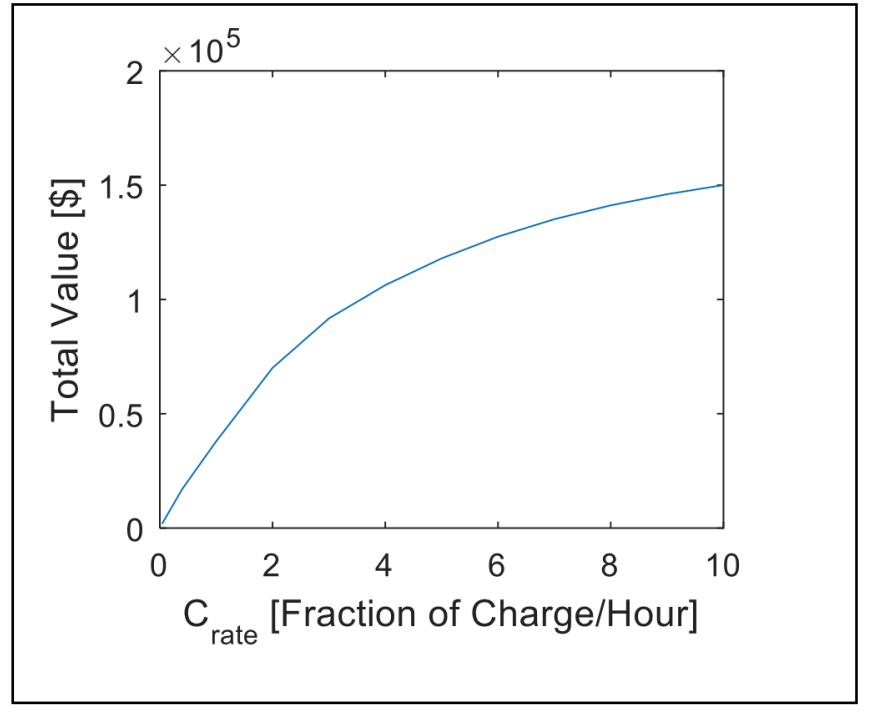

Figure 10: Effect of increasing the C-rate on the total value obtained through arbitrage.

Because the battery was assumed to operate at $100 \%$ coloumbic efficiency, the degradation effects were neglected. These effects often arise out of the thermal management issues associated with high rates of charge and discharge. While increasing the battery's $\mathrm{C}_{\text {rate }}$ directly leads to an increase in economic benefit that can be derived through arbitrage, it is unclear at what point the economic cost of operating the battery at high $\mathrm{C}_{\text {rates }}$ and high cycles would outweigh the benefits.

\subsection{Case Comparisons}

The results of the case comparisons were uniform. In each simulation the net value of the battery was consistent throughout the three cases. This indicates that each case, pure arbitrage, renewables firming, and peak shaving, the value of the system is the sum of the value of the 
system's components. The results did not reveal any synergistic benefit resulting from combining battery storage with generation or consumption. This indicates that a battery's value is independent of the generation or consumption that is connected to it. It also shows that in a real-time pricing market, there is no additional value to be gained through "renewables firming" or "peak shaving" beyond what the battery can provide through arbitrage independent of these applications.

The net value of the battery was the same in each of the three cases, pure arbitrage, renewables firming, and peak shaving. This result did not change throughout the seven simulations, no matter which system parameters were varied. This further supports the idea that the results of this study arise from the underlying mathematical principles of operating a battery in a RTP market in the absence of ramp rate penalties and peak demand charges. Table 13 shows the total economic value of the battery in each of the seven simulations.

Table 13: Value of battery for each simulation.

\begin{tabular}{|c|c|c|c|}
\hline \multicolumn{4}{|c|}{ Total Value of Battery for Each Simulation } \\
\hline Simulation & Description & $\begin{array}{c}\text { Net Battery } \\
\text { Value }\end{array}$ & $\begin{array}{c}\text { Net Battery } \\
\text { Value per MWh } \\
{[\mathbf{\$ M W h}]}\end{array}$ \\
\hline Simulation 1 & Basic Scenario & $\mathbf{\$ 1 3 , 7 6 5 , 0 0 1}$ & $\mathbf{\$ 2 8 , 6 7 7}$ \\
\hline Simulation 2 & V OC Variation & $\mathbf{\$ 6 , 8 8 2 , 5 0 1}$ & $\mathbf{\$ 2 8 , 6 7 7}$ \\
\hline Simulation 3 & Capacity Variation & $\mathbf{\$ 2 7 , 5 3 0 , 0 0 3}$ & $\mathbf{\$ 2 8 , 6 7 7}$ \\
\hline Simulation 4 & Pricing Data Variation & $\mathbf{\$ 1 3 7 , 6 5 0 , 1 4 6}$ & $\mathbf{\$ 2 8 6 , 7 7 1}$ \\
\hline Simulation 5 & Solar Data Variation & $\mathbf{\$ 1 3 , 7 6 5 , 0 0 1}$ & $\mathbf{\$ 2 8 , 6 7 7}$ \\
\hline Simulation 6 & Manufacturing Data Variation & $\mathbf{\$ 1 3 , 7 6 5 , 0 0 1}$ & $\mathbf{\$ 2 8 , 6 7 7}$ \\
\hline Simulation 7 & Seasonal Alignment & $\mathbf{\$ 1 3 , 7 6 5 , 0 0 1}$ & $\mathbf{\$ 2 8 , 6 7 7}$ \\
\hline
\end{tabular}


In the baseline scenario, the net value of the battery was $\$ 13,765,001$. Reducing the open circuit voltage by a factor of 0.5 directly reduced the total value that the battery could generate by that same factor, to a total value of $\$ 6,882,501$. Doubling the battery capacity from $1 \mathrm{MAh}$ to 2MAh without changing the $\mathrm{C}_{\text {rate }}$ approximately doubled the total value of the battery to $\$ 27,530,003$. The total value was slightly more than double the baseline scenario due to the $R_{\text {int }}$ being lower. When the pricing data was multiplied by a factor of ten, the total value of the battery increased by a factor of ten. This is because larger pricing differences directly lead to larger value from the battery. Variation of the solar and manufacturing plant data had no effect on the value of the battery. This again supports the principle that the battery's value is independent of the consumption and generation attached to it. And finally, aligning the datasets based on calendar year had no effect on the total economic value of the battery.

When the net battery value is analyzed on a per megawatt-hour basis, only variations in price effect the economic benefit that can be gained from each megawatt-hour of capacity. Increasing or decreasing the capacity of the battery did not change the net battery value per MWh, and the net value of the battery was completely unaffected by variations in consumption, generation, or season. All of these system variations support the conclusion that in an RTP market, a battery storage system makes its own business case, irrespective of generation or consumption connected to it.

This lack of synergistic behavior supports, for example, the potential benefits of utilizing existing battery resources for energy storage in a RTP market. Battery storage capacity that is already implemented, such as plug-in electric vehicles, could be leveraged to provide vehicle to grid services. As intermittent renewable energy reaches higher levels of market penetration, the existing energy storage capabilities of electric vehicle fleets can be leveraged to firm the supply. 
Because synergistic benefits do not exist in a RTP market, ancillary grid services could be provided by existing distributed storage systems without sacrificing economic value. Renewables firming and peak shaving can be accomplished through the function of the RTP market by energy storage systems that are integrated with or separate from electrical generation and consumption.

Even though there are no synergistic effects exhibited in the renewables firming or peak shaving cases in a RTP market, there is still a need for advanced energy storage to make widespread renewables possible. Combining battery storage with renewables does not increase the value of the renewable energy, but battery storage can still support renewables penetration by absorbing energy surpluses and mitigating shortages. Pricing variations in a RTP market are more indicative of surpluses and shortages in the energy supply than ramp rate penalties, which are fixed regardless of market needs [33]. Siting battery storage at a single renewable generation source could limit the potential renewables firming ability of that battery if it only stores energy from that one system. If the battery is engaged in arbitrage in a RTP market, it can leverage its entire value to support the market needs; otherwise, it may only utilize a portion of its capacity, and by extension, only a portion of its potential value.

In a RTP market, grid-scale battery storage can be sited throughout the grid without a loss of renewables firming capability. The results of this study demonstrate that the economic feasibility of renewable energy and battery storage are not dependent upon the location of the battery storage. This enables the advanced capabilities of the battery to be utilized for the maximum benefit of all stakeholders. Instead of utilizing a battery purely to firm a renewable energy source by slowing its ramp rates, batteries can leverage their fast response times to respond to variations in energy supply. Additionally, a disaggregated battery can be utilized to perform multiple 
ancillary services in order to increase the value of the battery system as a whole [34]. In a RTP market, grid-scale battery storage can be employed to maximize economic benefit in arbitrage without loss of renewables firming capability.

\subsection{Pricing Anomalies: Primary Drivers of Economic Value}

The results of the case comparisons reveal that pricing anomalies, short durations of very high or low prices relative to the prices surrounding that time period, are the most significant sources of economic benefit. Figure 11 demonstrates the optimal control of the system as it approaches a sharp spike in price. The pricing variations close to this price spike become

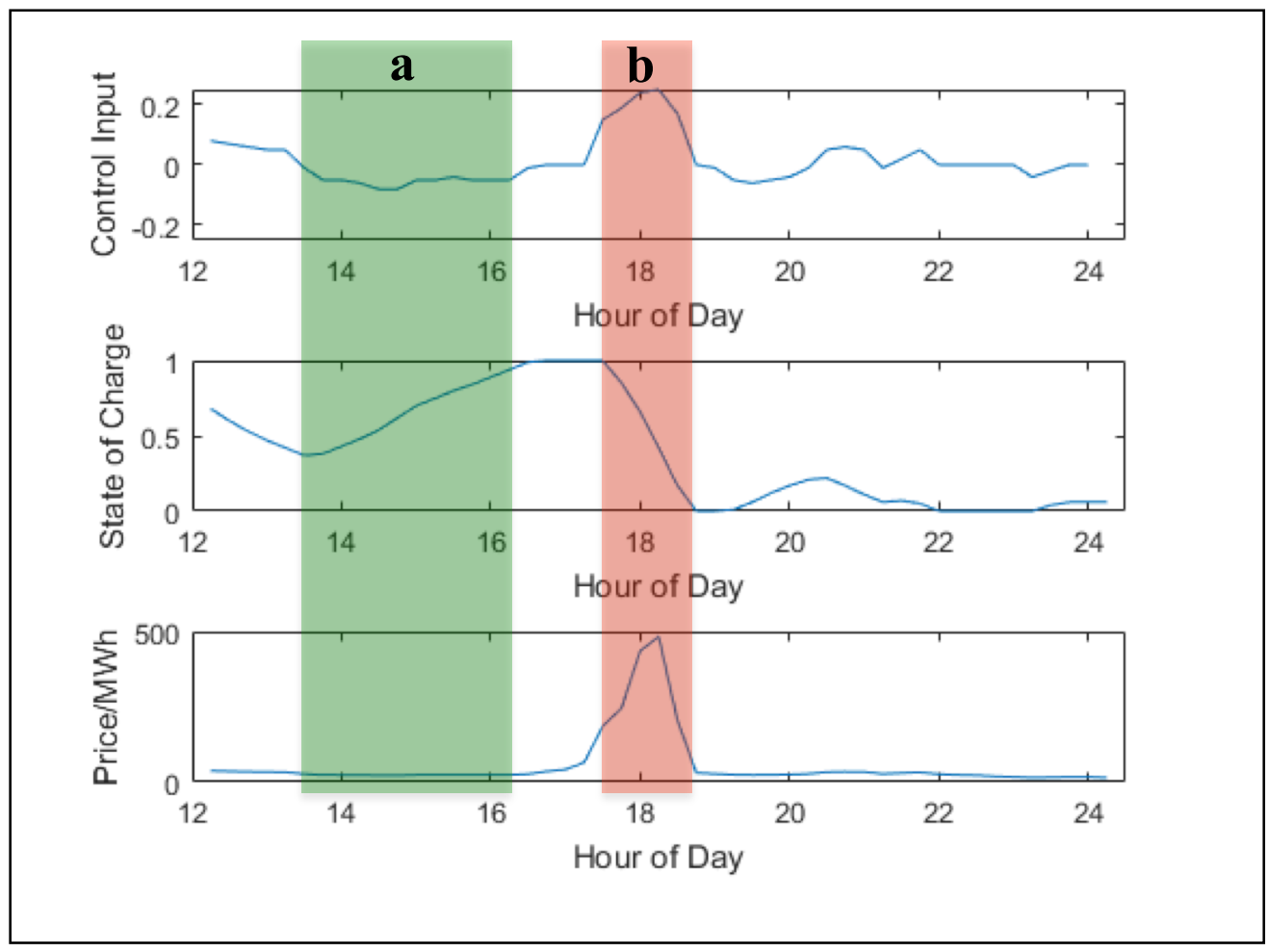

Figure 11: Battery storage energy to discharge during price spike event. Maximum price of approximately $\$ 500 / \mathrm{MWh}$.

negligible, and the battery stores energy during section $\mathbf{A}$, and then maintains maximum SOC in order to sell during the height of the anomaly in section $\mathbf{B}$. 
Conversely, Figure 12 demonstrates the optimal control of the system as it approaches a short duration of negative pricing. Negative costs of electricity are fairly common in the data set, and can arise from a variety of causes. Negative prices are typically caused by inflexibility of the

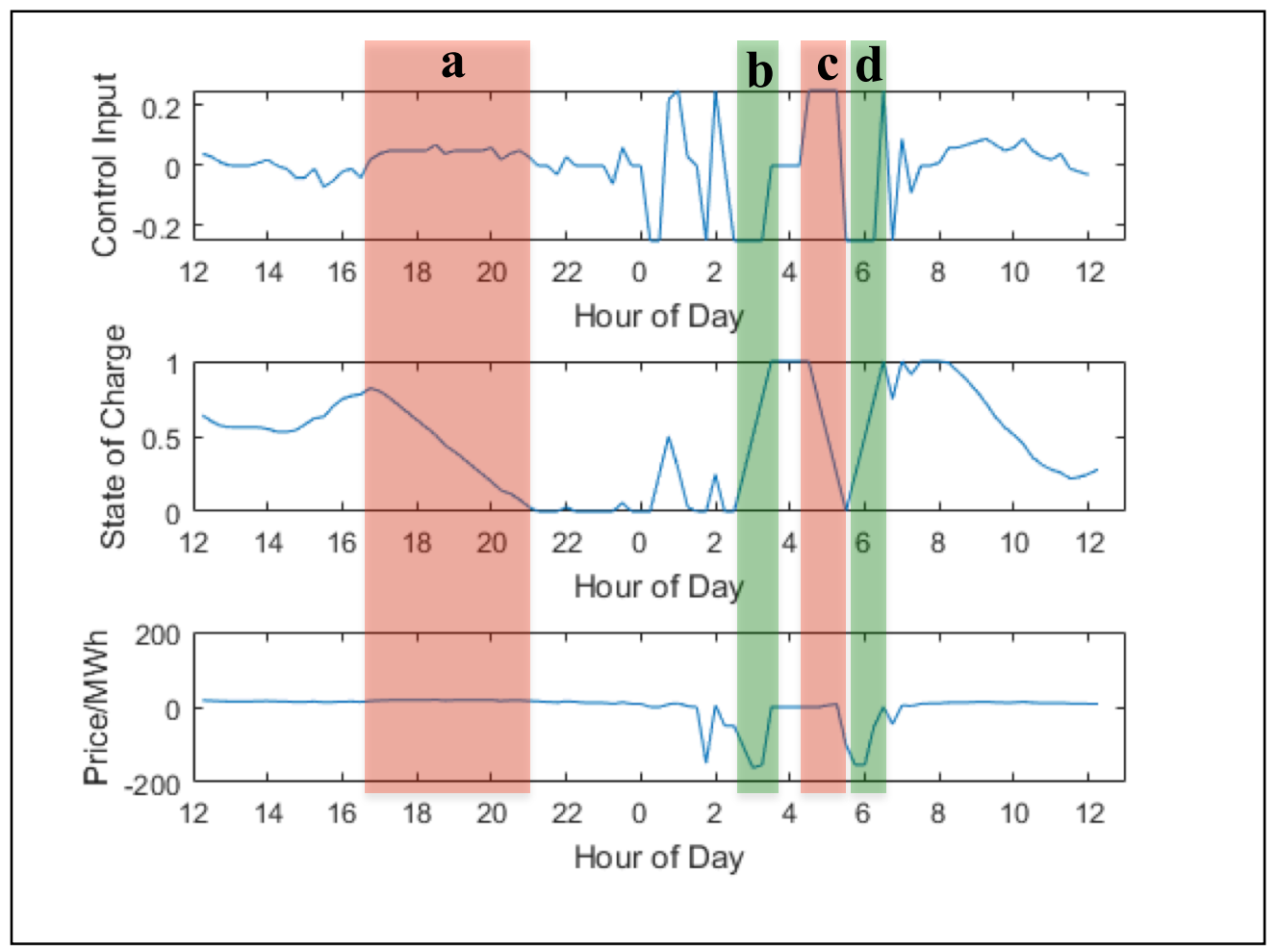

Figure 12: Negative pricing event. SOC decreases just before each price drop.

electrical supply [35]. For example, it may be more economical for a coal fired power plant to remain operational while customers are paid to consume the electricity generated, than to throttle back or shut down the power plant, and incur the high costs associated with startup. As the system approached this period of negative cost, the battery is discharged in order to purchase the low cost energy, illustrated in section A. Section B demonstrates how the battery moves from $0 \%$ SOC to $100 \%$ SOC during the negative pricing anomaly. The system then fully discharges in section $\mathbf{C}$ in order to again take advantage of the negative price of electricity in section $\mathbf{D}$. It is important to note that the selling of electricity in sections $\mathbf{B}$ and $\mathbf{D}$ occur at times of relatively 
low price, and it is the negative pricing anomaly that drives the selling of electricity in these cases.

In both instances of pricing anomalies, high and low, the optimal system control prepares for the change in pricing ahead of the actual pricing anomaly. This renders all pricing variations surrounding the anomaly negligible. This demonstrates the importance of the economic value that can be derived from these short durations of drastic pricing ${ }^{4}$.

\subsection{Daily Cycling Policy}

While pricing anomalies dominate other variation during the time surrounding the pricing event, there is sufficient time between anomalies for the system to extract value through arbitrage. Because daily pricing trends do not follow a set pattern, extracting value it is not as simple as buying electricity at night and selling it during the day. Figure 13 shows the SOC throughout a time period between anomalies. The battery cycles several times between these high price events, in response to small-scale price fluctuations. While the economic benefit derived from arbitrage in the absence of anomalies does yield high revenue per MAh, the high frequency of daily price variation allows it to contribute significant value to the total value that the energy storage system can generate.

\footnotetext{
${ }^{4}$ The economic value that can be captured by the battery would be reduced if operated in a market devoid of anomalies. As grid-scale energy storage implementation is increased to sufficiently high levels, the supply and demand curves will be smoothened, leading to a reduction in pricing variation. The effect of storage saturation was neglected for this study because the size of the battery was assumed to have a negligible impact on price. However, economic value could be impacted by sufficient grid connected battery storage systems through the reduction of anomalies.
} 


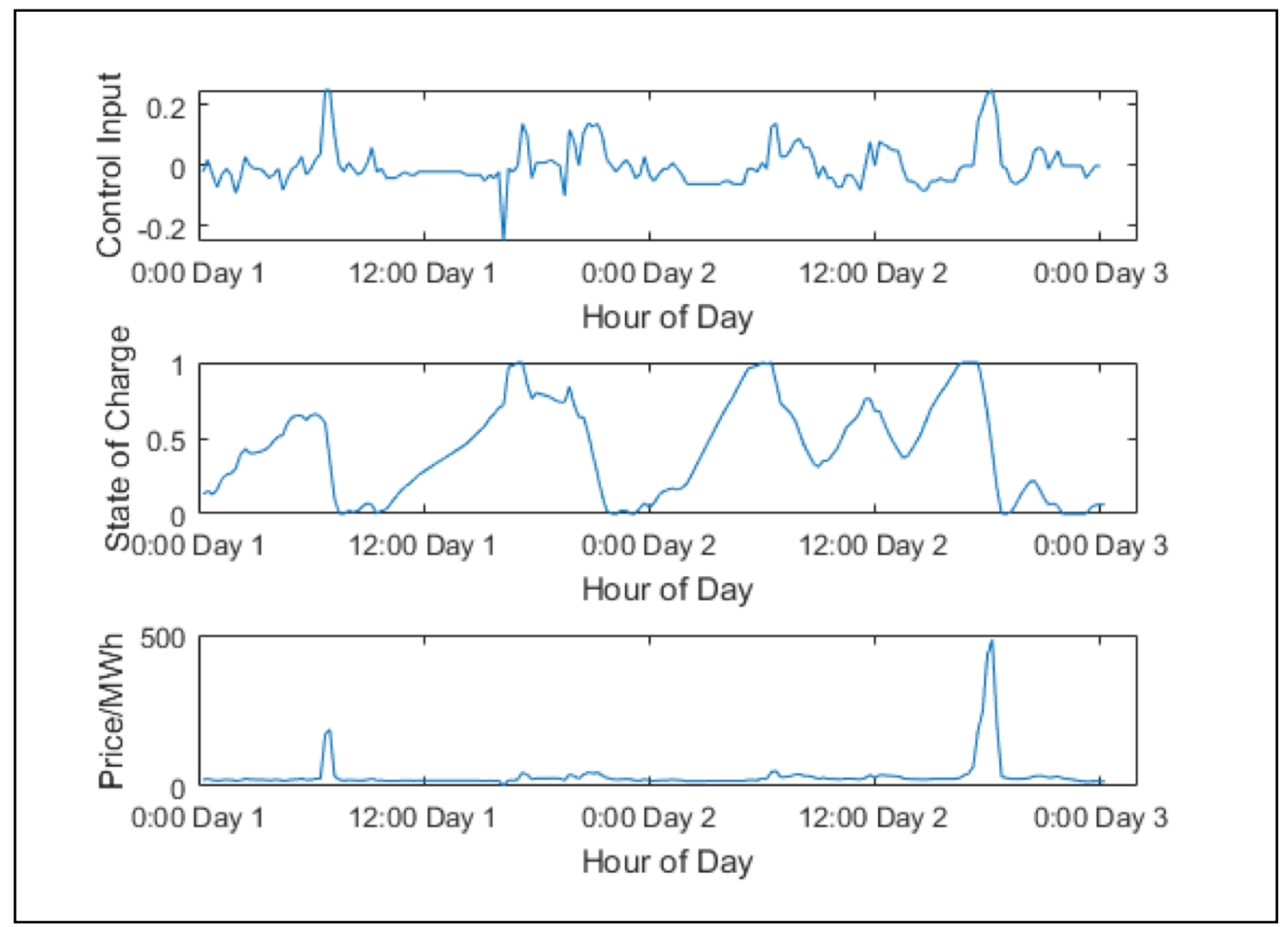

Figure 13: Results between anomalies. The system demonstrates several cycles of full charge and discharge between major pricing anomalies.

This study demonstrates that TOU rates do not accurately capture the daily pricing volatility. While TOU rates attempt to emulate the daily demand curve by setting, on-peak and off-peak prices, this study revealed that pricing can fluctuate high and low many times throughout a single day. The inflexibility of the electrical supply means that electrical demand is not the only factor effecting the cost of generating and distributing energy to customers. Instead, the cost is impacted by demand, supply, congestion, energy mix, and other factors. Because of this, pricing is much more volatile than demand.

\subsection{Negligible Seasonal Arbitrage}

Seasonal variations in price were shown to be completely inefficacious in generating value in this study. Prices were far too volatile for economic benefit to be derived by storing energy during one season of the year in order to sell it during another season. Figure 14 demonstrates 
how frequently the battery cycles throughout one week. If value were being derived from seasonal variations in price, the SOC of the battery would not fluctuate on a weekly basis, but would store energy for longer periods of time. Additionally, the number of cycles per year would be very low.

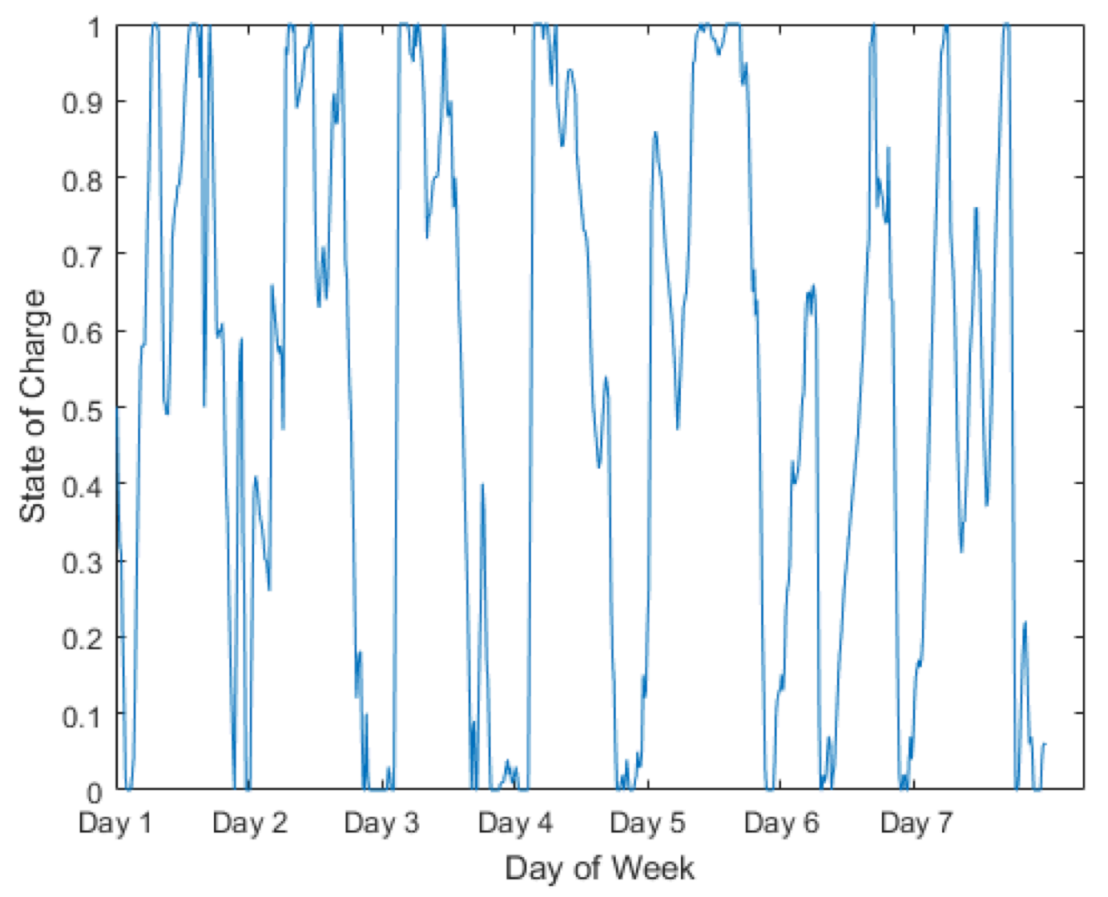

Figure 14: SOC for one week. Numerous fluctuations indicate that seasonal-scale storage is not an optimal strategy. 


\section{CONCLUSIONS}

This project reveals several characteristics of battery storage in a RTP market, most notably, the absence of synergistic effects when used in renewables firming and peak shaving applications. Additionally, short-term pricing anomalies were identified as the primary drivers of economic benefit, and maximizing $\mathrm{C}_{\mathrm{rate}}$ can enable a storage system to realize maximum value. The following section serves to answer the original research questions, which are restated here:

\section{Research Questions:}

1. Does there exist an economic benefit to coupling a battery storage system with intermittent electrical generation or manufacturing loads relative to a disaggregated grid-connect battery in a RTP market?

2. What are the primary drivers of economic benefit in a RTP market using grid-scale battery storage?

3. Which battery parameters can be optimized to maximize economic benefit of a battery storage system in a RTP market?

\subsection{Absence of Synergistic Effect of Renewables Firming and Peak SHAVING IN A RTP MARKET}

The primary conclusion that can be drawn from this analysis is that in a RTP market, the concepts of "renewables firming" and "peak shaving" do not realize value relative to a disaggregated grid-connected battery. Instead, the battery makes its own business case, providing economic benefit through arbitrage independent of the generation or consumption attached to it. 
In electricity markets where ramp rates and TOU rates are employed, batteries have been demonstrated to add some value associated with connecting them to renewables or to a manufacturing plant [16]. However, as more markets move towards RTP, the value derived from integrating batteries with renewables firming and peak shaving will disappear.

This does not discount the fact that increasing grid connection of intermittent renewables is causing a growing need for advanced energy storage capabilities. As battery storage becomes cost effective, it can be utilized throughout the grid in order to leverage its fast response time, low self-discharge rate, and scalability. This study suggests that because batteries can make their own business case, they can be implemented in a RTP market in a variety of configurations with the same economic benefit. Disaggregated batteries can also be employed to serve multiple grid services, such as frequency regulation, arbitrage, and power factor correction, in order to increase the economic value of the battery system.

\subsection{Optimal Control Policy}

Additional conclusions from this research can help grid-scale battery storage operators to make informed decisions on how best to manage energy storage for maximum economic benefit. System parameters and arbitrage control can be optimized as the sources of economic benefit are understood.

\subsubsection{Primary Drivers of Economic Benefit}

This project demonstrates that pricing anomalies, short durations of very high or low prices, are the primary drivers of economic benefit. The results of the DP simulations show that the most value can be made when the system buys and sells during pricing events that are extreme relative to the prices around them. The results of the optimization demonstrate that energy was 
stored as the simulation approached high price events, and energy was discharged as the simulation approached low price events; this indicates that the economic value of other variations become negligible near price anomalies.

The results show that daily variations do contribute to the total value, but only when they are not dominated by anomalies. Even though the daily price extremes are relatively low, their high frequency enables value to be derived between anomalies. It is important to note that daily price variations do not necessarily mimic daily demand cycles. A battery with a sufficiently high $\mathrm{C}_{\text {rate }}$ may cycle many times per day under the optimal control sequence, as it takes advantage of small fluctuations in price throughout the day. This frequent cycling renders seasonal pricing variations completely negligible. Battery storage operators can gain the most economic benefit by leveraging the fast response time of the battery to take advantage rapidly changing electricity prices, which are often short lived.

\subsubsection{Effects of $\mathrm{C}_{\text {rate }}$ on Total Value}

This study clearly shows the impact that $\mathrm{C}_{\text {rate }}$ has on the battery's ability to obtain value through arbitrage. Increasing the $\mathrm{C}_{\text {rate }}$ increases the total value significantly. With a higher $\mathrm{C}_{\text {rate, }}$, the battery can take advantage of uncharacteristically high and low prices of electricity, which do not last for very long. The high $\mathrm{C}_{\text {rate }}$ batteries can discharge or charge more fully during these short increments of very high or low prices, in order to maximize the value derived from them.

This effect is limited by the pricing structure, specifically how often the price of electricity changes. Increasing the $\mathrm{C}_{\text {rate }}$ beyond the point at which the battery can fully charge or discharge within the pricing time period does not increase the value due to arbitrage. It is important to remember that there are other costs associated with a high $\mathrm{C}_{\text {rate }}$ that were not considered in this study, including degradation and availability. 


\subsection{DiRECTION FOR FUTURE RESEARCH}

Several aspects of this project warrant further investigation in order to inform stakeholders of optimal system design and operation. The primary areas of future research are the effect of $\mathrm{C}_{\text {rate }}$ on the battery economic benefit, and regression analysis of the optimal control.

The effect of $\mathrm{C}_{\text {rate }}$ on battery cycle life should be investigated in order to accurately quantify the economic cost associated with operating at high rates and depths of charge and discharge. High current through a battery can cause significant thermal management problems, lead to a reduction in efficiency, and lead to premature failure. Deep discharge can also lead to reduced cycle life, further reducing economic value of the battery. To a certain extent, these negative impacts of high $\mathrm{C}_{\text {rate }}$ and deep discharge are acceptable as higher they enable the battery to extract more value through arbitrage. Understanding the economic impact of the effects of high current could help determine an optimal $\mathrm{C}_{\text {rate }}$ that maximizes economic benefit while accounting for the reduction in efficiency and cycle life.

Regression analysis of the optimal control of the battery storage system can lead to an optimization algorithm that can control without perfect forecasting. Regression analysis can provide the statistical support, based on electricity price and battery SOC, to determine the optimal times to charge and discharge the battery for the most economic benefit. By incorporating the cost of cycling, depth of discharge, and $\mathrm{C}_{\mathrm{rate}}$, an algorithm could be developed that would optimize the battery control in real time while minimizing the costs of battery cycle life degradation. 


\section{REFERENCES}

[1] A. Poullikkas, "A comparative overview of large-scale battery systems for electricity storage," Renew. Sustain. Energy Rev., vol. 27, pp. 778-788, 2013.

[2] I. Hadjipaschalis, A. Poullikkas, and V. Efthimiou, "Overview of current and future energy storage technologies for electric power applications," Renew. Sustain. Energy Rev., vol. 13, pp. 1513-1522, 2009.

[3] R. Dufo-lópez and J. L. Bernal-agustín, "Techno-economic analysis of grid-connected battery storage," Energy Convers. Manag., vol. 91, pp. 394-404, 2015.

[4] A. Zahedi, "Maximizing solar PV energy penetration using energy storage technology," Renew. Sustain. Energy Rev., vol. 15, no. 1, pp. 866-870, 2011.

[5] R. Carnegie, D. Gotham, D. Nderitu, and P. V Preckel, "Utility Scale Energy Storage Systems - Benefits, Applications, and Technologies,” 2013.

[6] M. Beaudin, H. Zareipour, A. Schellenberglabe, and W. Rosehart, "Energy storage for mitigating the variability of renewable electricity sources : An updated review," Energy Sustain. Dev., vol. 14, no. 4, pp. 302-314, 2010.

[7] A. Evans, V. Strezov, and T. J. Evans, "Assessment of utility energy storage options for increased renewable energy penetration," Renew. Sustain. Energy Rev., vol. 16, no. 6, pp. 4141-4147, 2012.

[8] F. Díaz-gonzález, A. Sumper, O. Gomis-bellmunt, and R. Villafáfila-robles, "A review of energy storage technologies for wind power applications," Renew. Sustain. Energy Rev., vol. 16, no. 4, pp. 2154-2171, 2012. 
[9] A. J. R. G. Ault, "Supporting high penetrations of renewable generation via implementation of real-time electricity pricing and demand response," no. February, pp. 369-382, 2010.

[10] National Renewable Energy Laboratory, "The Importance of Flexible Electricity Supply." pp. 1-4, 2011.

[11] H. Chen, T. Ngoc, W. Yang, C. Tan, and Y. Li, "Progress in electrical energy storage system : A critical review," Prog. Nat. Sci., vol. 19, no. 3, pp. 291-312, 2009.

[12] X. Han, M. Ouyang, L. Lu, J. Li, Y. Zheng, and Z. Li, "A comparative study of commercial lithium ion battery cycle life in electrical vehicle : Aging mechanism identi fi cation," J. Power Sources, vol. 251, pp. 38-54, 2014.

[13] B. Nykvist and M. Nilsson, "Rapidly falling costs of battery packs for electric vehicles," Nat. Clim. Chang., vol. 5, no. 4, pp. 329-332, Apr. 2015.

[14] A. Nottrott, J. Kleissl, and B. Washom, "Energy dispatch schedule optimization and cost benefit analysis for grid-connected, photovoltaic-battery storage systems," Renew. Energy, vol. 55, pp. 230-240, 2013.

[15] R. Dufo-lópez, "Optimisation of size and control of grid-connected storage under real time electricity pricing conditions," Appl. Energy, vol. 140, pp. 395-408, 2015.

[16] J. Leadbetter and L. Swan, "Battery storage system for residential electricity peak demand shaving," Energy Build., vol. 55, pp. 685-692, 2012.

[17] M. Bruch and M. Müller, "Calculation of the Cost-Effectiveness of a PV Battery System," vol. 46, pp. 262-270, 2014. 
[18] D. Wang, J. Coignard, T. Zeng, C. Zhang, and S. Saxena, "Quantifying electric vehicle battery degradation from driving vs . vehicle-to-grid services," J. Power Sources, vol. 332, pp. 193-203, 2016.

[19] C. G. $\tilde{A}$ and G. Gross, "A conceptual framework for the vehicle-to-grid ( V2G ) implementation," Energy Policy, vol. 37, no. 11, pp. 4379-4390, 2009.

[20] J. Tomi and W. Kempton, "Using fleets of electric-drive vehicles for grid support," vol. 168, pp. 459-468, 2007.

[21] H. Lund and W. Kempton, "Integration of renewable energy into the transport and electricity sectors through V2G,” vol. 36, pp. 3578-3587, 2008.

[22] A. Purvins, I. T. Papaioannou, and L. Debarberis, "Application of battery-based storage systems in household-demand smoothening in electricity-distribution grids," Energy Convers. Manag., vol. 65, pp. 272-284, 2013.

[23] G. P. Henze, "Impact of real-time pricing rate uncertainty on the annual performance of cool storage systems," vol. 35, pp. 313-325, 2003.

[24] S. P. Holland and M. T. Erin, "Is Real-Time Pricing Green ?: The Environmental Impacts of Electricity Demand Variance," 2004.

[25] R. Sioshansi and W. Short, "Evaluating the Impacts of Real-Time Pricing on the Usage of Wind Generation,” vol. 24, no. 2, pp. 516-524, 2009.

[26] W. W. Hogan, “Time-of-Use Rates and Real-Time Prices," Cambridge, Massachusetts, 2014.

[27] M. A. Bettencourt, J. E. Trancik, and J. Kaur, "Determinants of the Pace of Global 
Innovation in Energy Technologies," vol. 8, no. 10, 2013.

[28] W. A. Bra, J. M. Mueller, and J. E. Trancik, "Solar Energy," Nat. Clim. Chang., no. June, 2016.

[29] D. Schoenwald and J. Ellison, "Determination of Duty Cycle for Energy Storage Systems in a Renewables ( Solar ) Firming Application,” no. April, 2016.

[30] D. Lee, J. Kim, and R. Baldick, "Ramp Rates Control of Wind Power Output Using a Storage System and Gaussian Processes," pp. 1-22, 2012.

[31] T. E. Hoff, R. Perez, and R. M. Margolis, "Maximizing the value of customer-sited PV systems using storage and controls," Sol. Energy, vol. 81, pp. 940-945, 2007.

[32] ComEd, "Home / ComEd's Hourly Pricing Program," ComEd, 2017. [Online]. Available: https://hourlypricing.comed.com. [Accessed: 08-Feb-2017].

[33] A. Chitkara, D. Cross-Call, B. Li, and J. Sherwood, "A REVIEW OF ALTERNATIVE RATE DESIGNS INDUSTRY EXPERIENCE WITH TIME-BASED AND DEMAND,” Boulder, Colorado, 2016.

[34] T. Thien, M. Merten, and J. Münderlein, "Planning of Grid-Scale Battery Energy Storage Systems: Lessons Learned from a 5 MW Hybrid Battery Storage Project in Germany BESS applications," no. 3. pp. 1-10.

[35] P. Götz, D. J. Henkel, T. Lenck, and D. K. Lenz, "Negative Electricity Prices : Causes and Effects Negative Electricity - Prices : Causes and Effects,” Berlin, Germany, 2014. 


\section{APPENDIX}

\subsection{Appendix A Matlab Code}

This dynamic optimization code models the maximum economic benefit that can be derived from grid scale battery storage connected to the grid without any solar generation or plant consumption coupled with it.

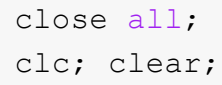

\section{User Inputs and Initial Calculations}

User Defined Battery Parameters

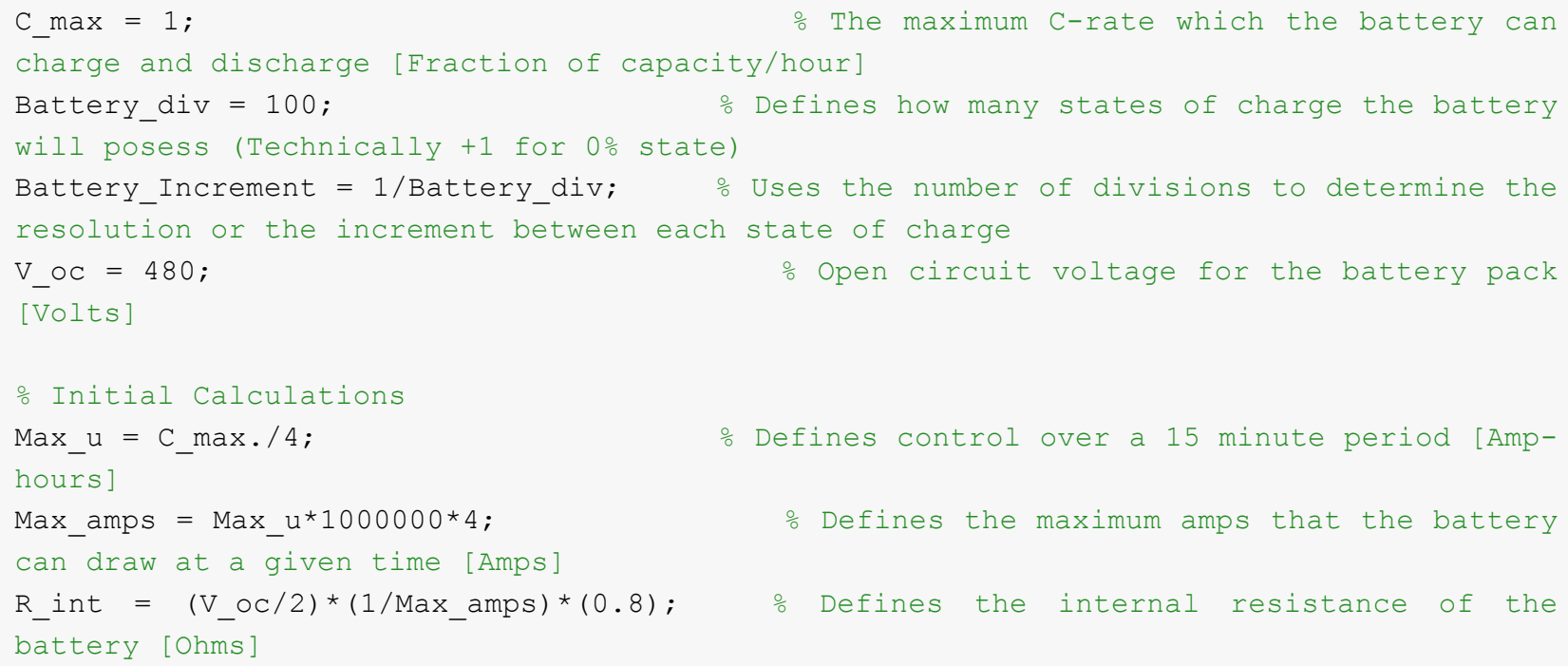

\section{Code Compatibility Checks}

Verify that Max_u is not larger than necessary for given 15 minute data

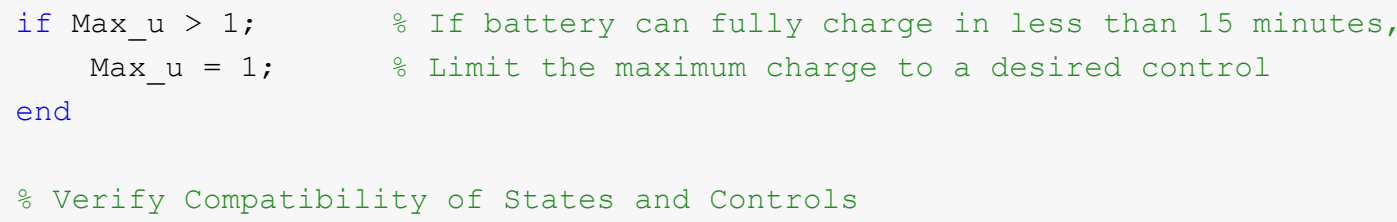




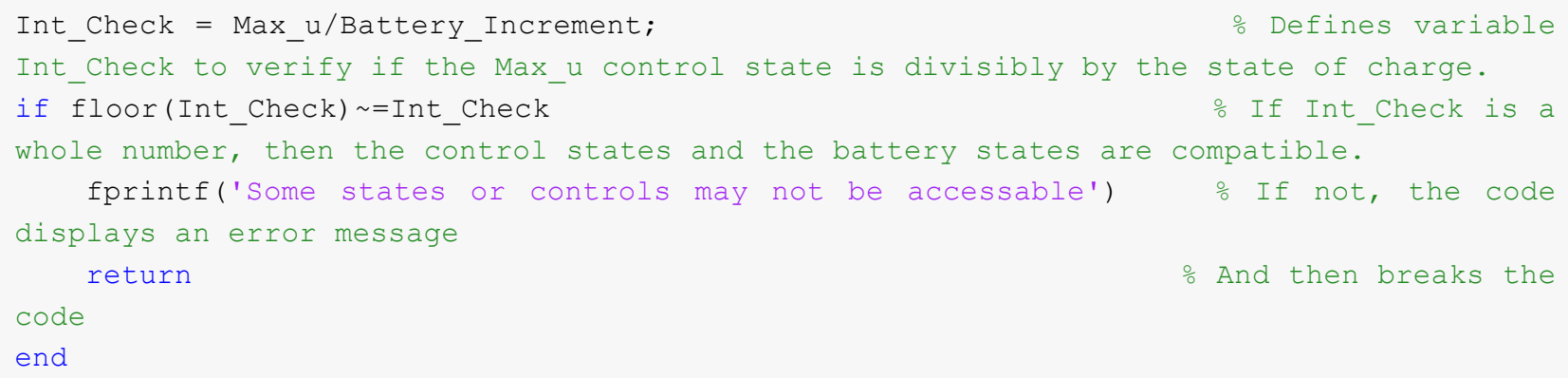

Loading exogenous data: Price, Solar Output, and Plant Consumption

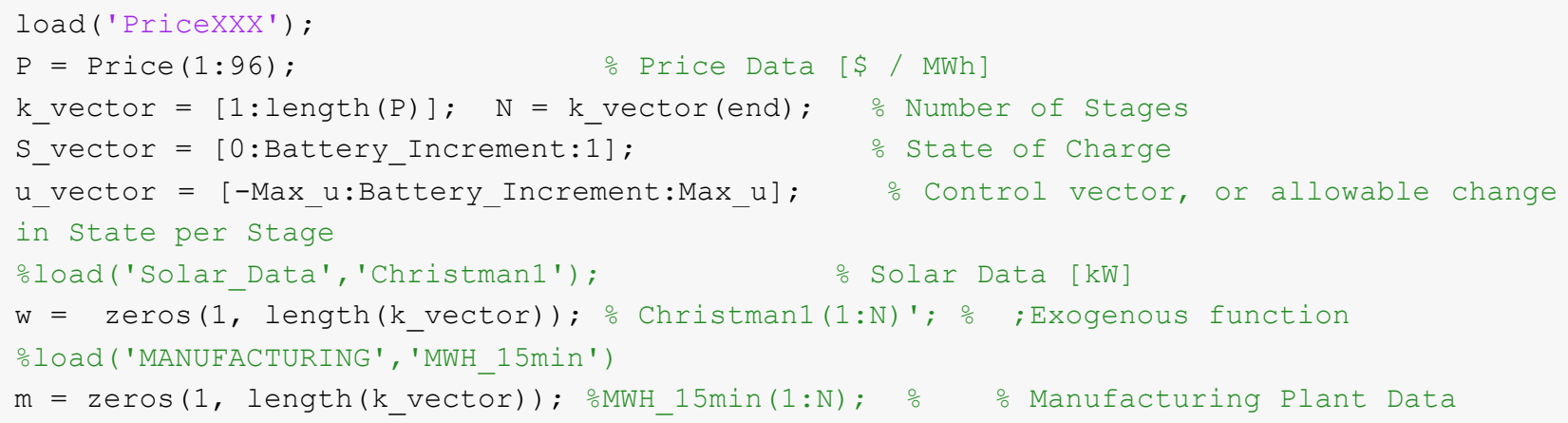

\section{Preparation for Dynamic Optimization}

Preallocating vectors

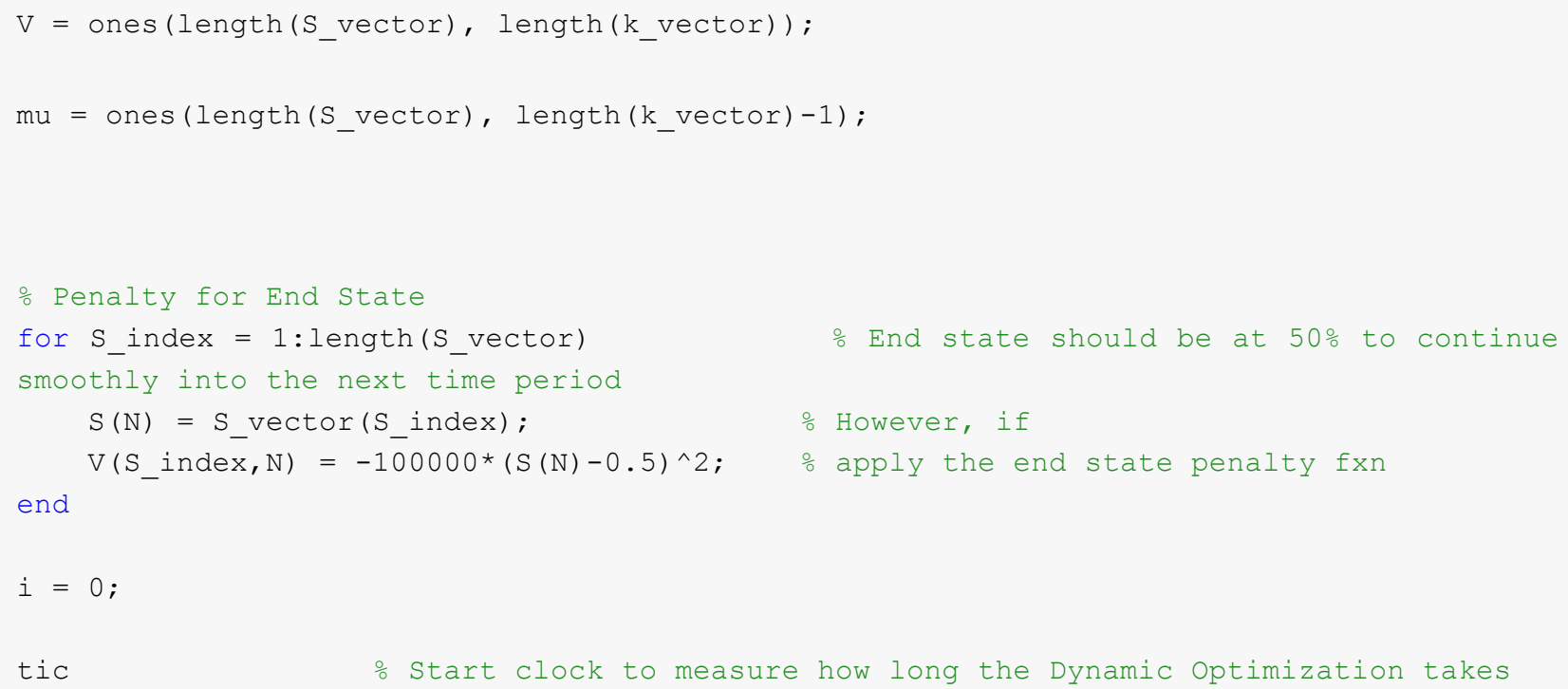

\section{Recursive Backwards Computation}




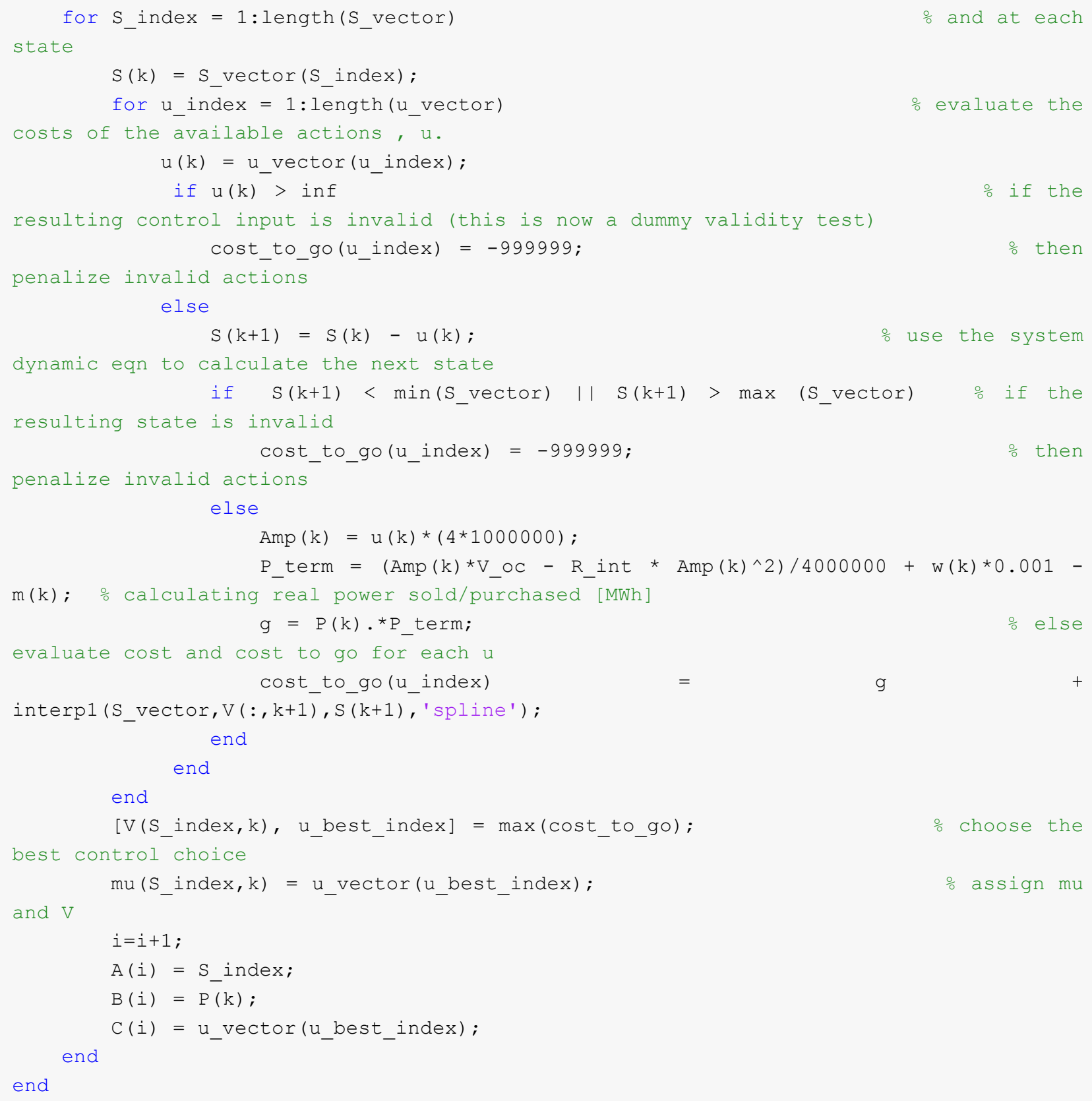

\section{Forward Recovery of Optimal States}

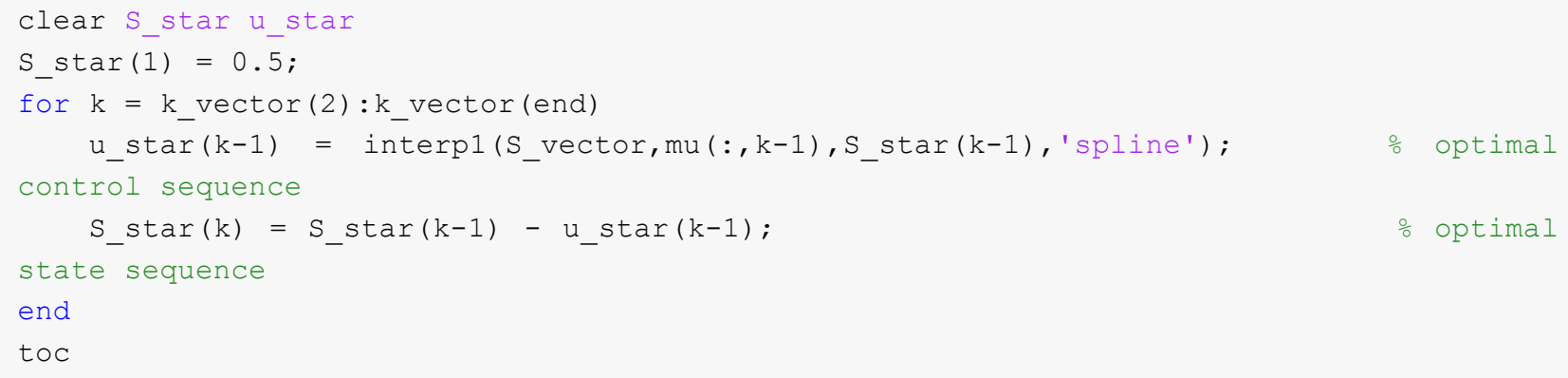


Elapsed time is 67.928088 seconds.

\section{Plotting Results and Saving}

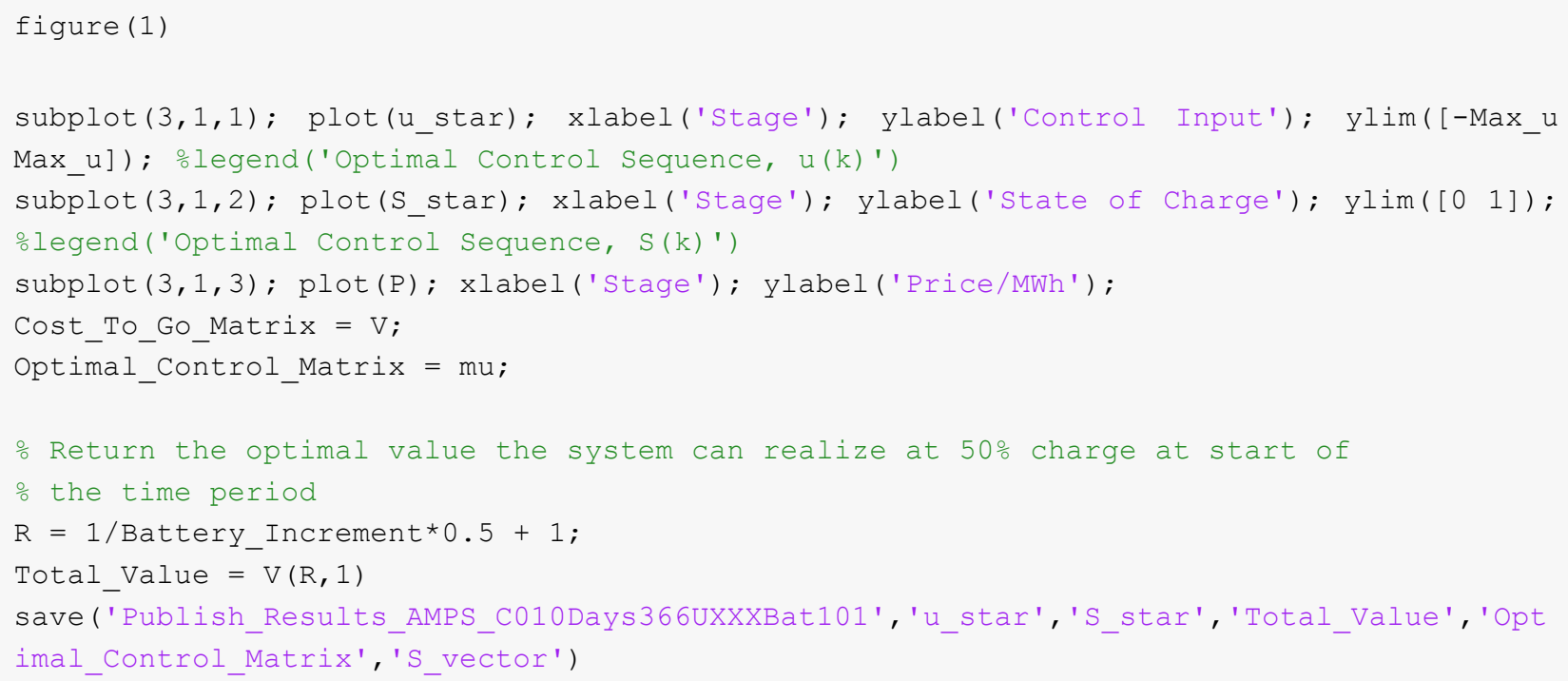

